Research Article

\title{
The sorption of Tebuconazole and Linuron from an Aqueous Environment with a Modified Sludge-Based Biochar: Effect, Mechanisms, and Its Persistent Free Radicals Study
}

\author{
Jingjie Yang $\mathbb{D},{ }^{1}$ Hongwei Sun, ${ }^{1}$ Yucan Liu, ${ }^{2}$ Xiaohan Wang, ${ }^{3}$ and Kamran Valizadeh $\mathbb{D}^{4}$ \\ ${ }^{1}$ College of Environmental and Material Engineering, Yantai University, Yantai, Shandong 264005, China \\ ${ }^{2}$ College of Civil Engineering, Yantai University, Yantai, Shandong 264005, China \\ ${ }^{3}$ China Automative Technology and Research Center Co., Ltd, Beijing 100000, China \\ ${ }^{4}$ Department of Chemical Engineering, Science and Research Branch, Islamic Azad University, Tehran, Iran
}

Correspondence should be addressed to Jingjie Yang; yangjingjieytu@163.com and Kamran Valizadeh; valizadeh.che2019@gmail.com

Received 30 August 2021; Revised 29 October 2021; Accepted 2 November 2021; Published 29 November 2021

Academic Editor: Saima Q. Memon

Copyright (c) 2021 Jingjie Yang et al. This is an open access article distributed under the Creative Commons Attribution License, which permits unrestricted use, distribution, and reproduction in any medium, provided the original work is properly cited.

\begin{abstract}
In this study, the sludge-based biochar was prepared and utilized as an adsorbent for the removal of two commonly used pesticides in agriculture, namely tebuconazole (Teb) and linuron (Lin) in an aqueous solution. The main contributing factors such as biochar preparation conditions, persistent free radicals as well as contact time, agitation speed, biochar dose, temperature, and $\mathrm{pH}$ were investigated. The physicochemical properties were characterized by SEM + EDS, FTIR, BET, EPR, etc. The results showed that the maximum adsorption capacities based on the Langmuir model was $7.8650 \mathrm{mgg}^{-1}$ for tebuconazole and that based on Freundlich model was $9.0645 \mathrm{mg} \cdot \mathrm{g}^{-1}$ for linuron at $25^{\circ} \mathrm{C}$. The pseudo-second-order kinetic equations were all fitted well to the kinetic process of the adsorption of the two pesticides with all $R^{2} \geq 0.915$. The maximum

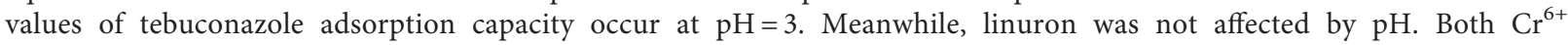
$\left(r=-0.793^{* *} /-0.943^{* *}\right)$ and humic acid $\left(r=-0.798^{* *} /-0.947^{* *}\right)$ significantly inhibited the adsorption amount of tebuconazole and linuron onto the biochar. Electron spin resonance signals (ESR) indicated that environmentally persistent radicals (EPFRs) are preferentially formed at lower pyrolysis temperatures and lower transition metal concentrations. The g-factors for $\mathrm{BC} 400, \mathrm{BC} 600, \mathrm{BCF} 400$, and BCF600 were 2.0036, 2.0035, 2.0034, and 2.0033, respectively, indicating that the EPFRs mainly have a carbon-centered structure with adjacent oxygen atoms. In addition, to close to the actual situation, natural water (from YanTai) was collected to simulate pesticide contamination. This study demonstrates that sludge-based biochar can achieve efficient removal of tebuconazole and linuron in aqueous environment in a short period of time with no secondary environmental risk especially on the waste activated sludge.
\end{abstract}

\section{Introduction}

The production status of agriculture strongly depends on the use of pesticides [1-7]. Because of the continuously growing population and the progress of modern agriculture, pesticides have played a crucial role in producing high crop yields, preventing diseases and controlling pests [8-13]. Tebuconazole [(RS)-1-p-chlorophenyl-4, 4-dimethyl-3- $(1 \mathrm{H}$ 1, 2, 4-triazol-1-ylmethyl)-pentan-3-ol] is a high-efficiency, broad-spectrum, and inhalant triazole bactericidal pesticide [14-19]. With the function of inhibiting the biosynthesis of ergosterol in fungi, it acts as a frequently used fungicide for the protection of crops (oilseed rape, hop, grape vine, peanuts, vegetables, etc.) and wooden materials. Linuron (3(3, 4-dichlorophenyl)-1-methoxy-1-methylurea) is applied to the restrained annual gramineous weeds for the sake of economical crop growth (celery, legume, carrot, potato, onion fields, etc.). However, because of their physical and 
chemical properties, high toxicity, and occasionally high endurance in the environment, these pesticides may cause environmental and health problems [20-26]. Agricultural runoffs and toxic industrial wastewater are two main ways for pesticides to enter natural water [27-35]. There is accumulating evidence that pesticides are widely detected at $\mu \mathrm{g} \cdot \mathrm{L}^{-1}$ levels in the rivers, soils, as well as other environmental compartments, while some compounds are considered reprotoxic [36-38]. Therefore, researchers are working to develop effective remediation methods or new materials to remove the pesticide residues from aqueous environments [39-44].

In recent years, studies have shown that the use of lowcost adsorbents for water decontamination is a major development trend with high efficiency and economy [45-51]. Biochar is a kind of carbon-rich material obtained by the pyrolysis of biomass in an anaerobic or anoxic environment at high temperatures (mostly lower than $700^{\circ} \mathrm{C}$ ) $[52,53]$. Chemical activation and modification are commonly used to produce activated carbon, and they require immersion stirring with chemicals, such as $\mathrm{KOH}, \mathrm{FeCl}_{3}$, or $\mathrm{HCl}$ [54-56]. Through these processes, the biochar usually possesses a relatively high specific surface area, abundant pore structures, and rich functional groups, and the weak force between the biochar and target pollutants can be transformed into a strong force (electrostatic effect, chelation, hydrophobic effect, etc.) [57]. Although activated carbon has been promoted on a large scale, it, in some aspects, is still limited because of the high cost of production and regeneration [58]. Thus, the preparation of low-cost adsorbents from different waste materials (domestic, agricultural waste, or industrial byproducts) [59-61] is more economical and environmentally advantageous.

Excess sludge is one of the components of sewage sludge [62]. In China, approximately $180,000 t$ of dried sludge is generated annually, and the number is still on the rise [63]. Untreated excess sludge has previously been applied as an organic additive to agricultural soils with some success, but the slow release of toxic metals and some hazardous compounds has caused more serious and potential ecological risks [64]. Therefore, this type of recycled material has to be carbonized before further usage to destroy or stabilize the microorganisms (especially pathogenic bacteria), hazardous organic matter, and toxic metals [65].

This study addresses the problem of reusing excess sludge for the purpose of biochar production by sludge carbonization to purify water bodies contaminated with tebuconazole and linuron. The adsorption effects and extrinsic conditions affecting the adsorption and material characteristics were evaluated and explored, and the removal mechanisms of tebuconazole and linuron were further obtained. Then, the environmentally persistent free radicals (EPFRs) of sludge biochar were explored, which was less reported in the previous studies. At the same time, the experiment of metal ion leaching was carried out to ensure that biochar will not cause secondary pollution while treating water pollution. The aforementioned studies have some degree of practical significance for truly achieving waste sludge resource reduction.

\section{Materials and Methods}

2.1. Materials. The dewatered waste activated sludge was obtained from the municipal (AAO + deep bed filter) wastewater treatment plants (WWTPs) located in Yantai, Shandong Province, China. After drying in the oven at a constant $70^{\circ} \mathrm{C}$ overnight, the solid sludge block was obtained. Then, it was smashed by a household food mincer, sieved through 100 mesh size $(0.150 \mathrm{~mm})$, and stored in a quartz beaker equipped with a thin film of biomass for further use. The supplier of methanol and acetonitrile of HPLC grade was Fisher Scientific Worldwide (Shanghai) Co., Ltd. Tebuconazole was purchased from Aladdin Biochemical Technology Co., Ltd. (Shanghai, China) and linuron was supplied by Sigma-Aldrich Trading Co., Ltd. (Shanghai, China) with a purity of analytical standard. Their particle morphologies and three-dimensional (3D) structures are shown in Figure 1. All other required chemical reagents, including $\mathrm{NaOH}, \mathrm{HCl}, \mathrm{FeCl}_{3}$, and humic acid, were purchased from China National Pharmaceutical Group Co. Ltd. These chemicals were of analytical grade. Deionized water $(18 \mathrm{M} \Omega)$ used in this experiment was generated from a Milli-Q system (Merck Millipore, USA).

2.2. Preparation of Biochar/Magnetic Biochar. Biochar: the sludge powder was placed inside a quartz crucible, compacted, and pyrolyzed in a tube furnace under the protection of nitrogen $\left(200 \mathrm{ml} \cdot \mathrm{min}^{-1}\right)$. The temperatures of the tube furnace were set to 400 and $600^{\circ} \mathrm{C}$, respectively, with the heating and cooling rates of $5^{\circ} \mathrm{C} \mathrm{min}^{-1}$, and maintained for 2 hours. After coming to room temperature, the biochar was subsequently rinsed three times with $1 \mathrm{M} \mathrm{HCl}$ and deionized water until the supernatants of the solution approached neutrality. The biochar suspension was centrifuged at $5000 \mathrm{rpm}$, and the supernatant was discarded. The remaining pastes were spread in several glass culture dishes and dried overnight at $60^{\circ} \mathrm{C}$ to obtain the experimental biochar (named BC400, BC600).

Magnetic biochar: to reduce the chemical reagent usage and save costs, the ratio of biochar to iron ion in $1: 0.25$ was used to prepare the magnetic biochar. The specific procedures were as follows: $500 \mathrm{ml}$, containing $2.07 \mathrm{~g}$ of $\mathrm{FeCl}_{3}$ solution was configured first; after being uniformly weighed, $5 \mathrm{~g}$ of sludge powder was dissolved in $500 \mathrm{ml}$ of the aforementioned solution and stirred at an appropriate rotation speed for $15 \mathrm{~min}$ to be fully mixed. Then, the mixed liquor was put into an ultrasonic cleaner for $30 \mathrm{~min}$. After that, stirring was continued for $12 \mathrm{~h}$ with a magnetic stirrer at $60^{\circ} \mathrm{C}$, other steps were the same as the biochar preparation process above to obtain the experimental magnetic biochar (named BCF400 and BCF600).

2.3. Characteristics of Biochars. A series of characterization methods were used to study the physiochemical properties of four materials: BC400, BC600, BCF400, and BCF600. The elemental composition, characteristic images, and sample morphologies were detected by the scanning electron microscopy equipped with an energy dispersive spectrometer 


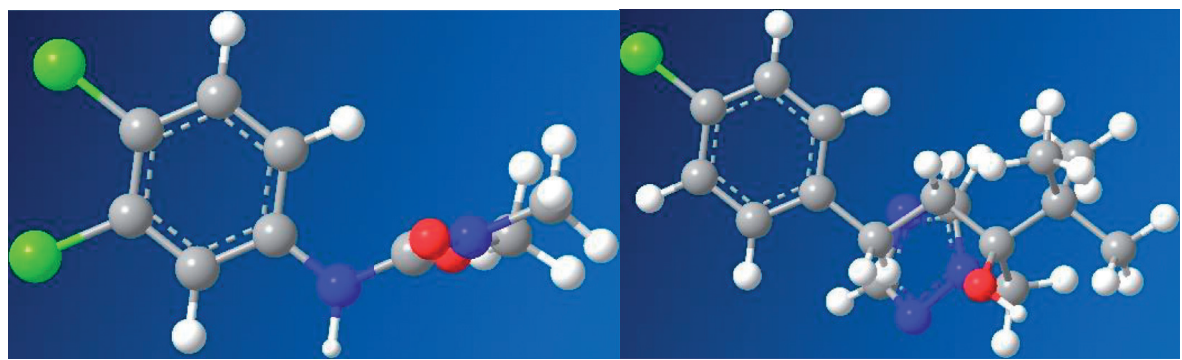

Figure 1: Tebuconazole (a) and linuron (b) particle morphologies and three-dimensional (3D) structures.

(SEM-EDS, Zeiss Sigma 500, Germany), FTIR (Thermo Fisher, Nicolet iS5, USA) for the surface functional groups of the materials, BET (ASAP2460, Micromeritics, USA) for specific surface area, pore size distribution, and pore volume of the prepared adsorbent samples (mass of biochar: $0.9651 \mathrm{~g}$, degassing temperature: $300^{\circ} \mathrm{C}$ for $6 \mathrm{~h}$ ), XRD (Smart Lab 9, Rigaku Corporation, Japan) for crystalline phase structure, and VSM (SQUID-VSM, Quantum Design, USA) for magnetic performance. The ESR signals were obtained using an electron spin resonance spectroscopy (EMX Plus, Bruker, Germany). The scanning width, central magnetic field, and modulation frequency were $100 \mathrm{GT}, 3510 \mathrm{GT}$, and $100 \mathrm{kHz}$, respectively. ICP-MS (Agilent 7700, America) was used to determine the concentration of the metal ion in supernatants for the leaching experiments.

\subsection{Adsorption Experiments}

2.4.1. Batch Experiments. Batch experiments were conducted to study the effects of reaction balance time, dosage of biochar, $\mathrm{pH}$ value, coexisting inorganic and organic concentrations, table rotational speed, and reaction temperature during the adsorption process. In addition, to ensure the precision of the data, two independent parallel experiments were performed on each group, and each experiment was performed in triplicate and calculated to obtain an average. Two kinds of pesticide solution $\left(20 \mathrm{mg} \mathrm{L}^{-1}\right)$ were prepared with deionized water as the stock solution and placed in a brown bottle away from light at $4{ }^{\circ} \mathrm{C}$ for later use. The adsorption experiments were applied at different $\mathrm{pH}$ values through $0.1 / 1.0 \mathrm{~mol} \cdot \mathrm{L}^{-1} \mathrm{HCl}$ and $\mathrm{NaOH}$ ranging from 3.0 to 10.0 to analyze the effect of $\mathrm{pH}$ on the adsorption process: mixed $0.075 \mathrm{~g}$ adsorbent material and $100 \mathrm{ml}$ of solution with a concentration of $10 \mathrm{mg} \mathrm{L}^{-1}$ into a conical bottle with plug. All the samples were then incubated in a water bath shaker at $180 \mathrm{rpm}$ maintained at a constant temperature of $25{ }^{\circ} \mathrm{C}$. After the reaction, the supernatants were collected by centrifuging at $5000 \mathrm{rpm}$ for $5 \mathrm{~min}$ and filtrating with $0.22 \mu \mathrm{m}$ filter membrane. The pesticide concentrations were measured by high-performance liquid chromatography/ mass spectrometry (HPLC-MS). The effect of metal salt ionic strength on the adsorption effect were tested by varying the ion concentration $(0,5,10,30 \mathrm{mg} / \mathrm{L})$, and for organics, the concentration gradient was set as $0,5,10,50 \mathrm{mg} / \mathrm{L}$ with $\mathrm{pH}$ unadjusted. Meanwhile, we also tested the removal of pesticides under real water environment. To optimize the reaction conditions, the shaker rotation rate: $90-240 \mathrm{rpm}$ with an interval of 30 was also considered. Other experimental conditions were the same as those in the $\mathrm{pH}$ experiments.

The leaching experiments were also carried out to evaluate whether the biochar caused secondary pollution. After $48 \mathrm{~h}$ of reaction with the optimized shaker rpm, biochar dosage, and no pesticides added, the supernatants were collected for metal ion determination.

2.4.2. Sorption Kinetics. Kinetic studies were carried out with two different solutions $(5,20 \mathrm{mg} / \mathrm{L})$ of the two kinds of pesticides. $150 \mathrm{ml}$ of the corresponding pesticide solution along with $0.075 \mathrm{~g}$ of the adsorbent material was added to the 200-mL conical bottle. The mixture was then reacted continuously with $180 \mathrm{rpm}$ for $6 \mathrm{~h}$ in a water bath shaker at $25^{\circ} \mathrm{C}$, and the samples were taken at specific time points. The samples were performed in the same manner as the $\mathrm{pH}$ experiment described.

2.4.3. Adsorption Isotherms. The adsorption isotherm experiments were performed at the temperature of 25, 35, and $45^{\circ} \mathrm{C}$, and the concentrations of pesticide solutions were added according to the gradients, which were $2-20 \mathrm{mg} \mathrm{L}^{-1}$, respectively. The adsorbent material $(0.075 \mathrm{~g})$ and $100 \mathrm{~mL}$ of pesticide solution were mixed in the $150 \mathrm{~mL}$ conical flask. Then, the conical flask was put in the water bath shaker and rotated at $180 \mathrm{rpm}$ for $6 \mathrm{~h}$. The samples were performed in the same manner as the $\mathrm{pH}$ experiment described.

2.5. Analytical Methods. The concentration of tebuconazole (Teb) and linuron (Lin) in the aqueous phase was determined by an HPLC (Xevo TQD, Waters Corp., Milford, MA, USA) equipped with a C-18 column (ACQUITY UPLC BEH C18 $1.7 \mu \mathrm{m}$ XB-C18, Waters Inc.). The LC column temperature was maintained at $40^{\circ} \mathrm{C}$. The mobile phase was methanol and water with a linear isocratic ratio of $40: 60$. The flow rate was $1.0 \mathrm{ml} \cdot \mathrm{min}^{-1}$, and the injection volume was $10 \mu \mathrm{L}$. To avoid the trace amounts of photodegradation, all experimental procedures performed were protected from light, and the blank samples were used to avoid errors from actual hydrolysis. The actual results showed that the photolysis and hydrolysis of tebuconazole and linuron in the aqueous phase were negligible. 
The removal and uptake of tebuconazole and linuron after the adsorption was calculated by the following equation:

$$
\begin{aligned}
q_{e} & =\frac{C_{0}-C_{e}}{m} V, \\
\eta & =\frac{C_{0}-C_{e}}{C_{0}} \times 100 \% .
\end{aligned}
$$

where $q_{e}$ is the adsorption capacity of BCF600 to Teb and Lin when the reaction reaches an equilibrium, $\mathrm{mg} \cdot \mathrm{g}^{-1} ; C_{0}$ and $C_{e}$ represent the initial and the equilibrium remaining concentration of Teb and Lin, mg. $\mathrm{L}^{-1} ; V$ is the total volume of the solution, $L ; m$ indicates the amount of adsorbent material administered, $g$; and $\eta$ is the removal rate or adsorption rate.

The equations of kinetics and isotherm models are listed in Table 1.

Isotherm models: $q_{m}=$ maximum adsorption capacity $\left(\mathrm{mg} \cdot \mathrm{g}^{-1}\right), K_{L}=$ Langmuir adsorption isotherm constant, $\mathrm{Ce}=$ pesticides concentration of solution at equilibrium $\left(\mathrm{mg} \cdot \mathrm{L}^{-1}\right), \quad K f=$ Freundlich adsorption coefficient $\left(\mathrm{mg}^{1-\mathrm{n}} \cdot \mathrm{g}^{-1} \mathrm{~L}^{-\mathrm{n}}\right), \quad n=$ Freundlich constant, and $K_{S}$ and $m=$ Sips model constants.

Kinetic models: $t=$ time $(\mathrm{min}), q_{e}=$ adsorption capacity $(\mathrm{mg} / \mathrm{g})$ at equilibrium time, $q_{t}=$ amount of pesticides adsorbed at any time $t\left(\mathrm{mg} \cdot \mathrm{g}^{-1}\right), K_{1}=$ pseudo-first-order rate constant $\left(\mathrm{min}^{-1}\right), K_{2}=$ pseudo-second-order rate constant $\left(\mathrm{g} \cdot \mathrm{mg}^{-1} \cdot \mathrm{h}^{-1}\right), \quad a=$ rate constant of chemisorption, and $b=$ constant of the surface coverage.

To explore the influence of the concentrations of coexisting organics and inorganics on the sorption of the two pesticides on BCF600, four different concentration gradients of each substance with a corresponding 16-unit sorption were subjected to a univariate correlation analysis. All the data were processed using SPSS (IBM SPSS Statistics $20.0)$ and the significant changes $\left({ }^{*} P<0.05,{ }^{* *} P<0.01\right.$, and $\left.{ }^{* * *} P<0.001\right)$ were indicated throughout [68].

\section{Results and Discussion}

\subsection{Removal Experiments}

3.1.1. Optimal Preparation Conditions for Biochar. The effect of the different preparation conditions of biochars on the removal of tebuconazole and linuron is shown in Figure 2. For tebuconazole, compared with BC400, BC600, and BCF400, BCF600 showed a significant improvement on tebuconazole removal. Under the condition of $0.1 \mathrm{~g}$ BCF600 dosage, the tebuconazole concentration reduced to $0.37 \mathrm{mg} \cdot \mathrm{L}^{-1}$ from $5 \mathrm{mg} \mathrm{L}^{-1}$ in $60 \mathrm{~min}$, and the tebuconazole removal efficiency was finally $99.83 \%$ six hours after the reaction fully equilibrated. However, the removal efficiencies of BC400, BC600, and BCF400 biochar were only $31.19 \%$, $29.90 \%$, and $35.75 \%$ in $120 \mathrm{~min}$, respectively. The final results showed that the adsorption amount of tebuconazole by BCF600 was approximately 1.82, 2.49, and 2.93 times higher than the maximum adsorption amount of BC400, BC600, and BCF400 in $360 \mathrm{~min}$. The same trend was observed for the linuron adsorption. Together, the evidence suggested that for the biochar, a higher preparation temperature and ferric chloride modification could enhance the removal ability of tebuconazole and linuron. Hence, BCF600 was selected as the adsorbent material for the subsequent experiments to achieve a better adsorption effect.

3.1.2. Effect of Biochar Dosage and Agitation Speed. Biochar dosage was a key factor influencing tebuconazole and linuron adsorption. The initial concentration of tebuconazole and linuron solution was at a constant $10 \mathrm{mg} \mathrm{L}^{-1}$. When the dosage of BCF600 was $0.25-0.125 \mathrm{mg} \mathrm{L}^{-1}$, the removal rate of tebuconazole and linuron gradually reached $87.83 \%$ and $95.0757 \%$, respectively. However, as BCF600's mass increased, the adsorption amount per unit mass of the adsorbent decreased. The removal rate increases with the increase of adsorbent mass mainly because of the more binding sites on the adsorbent. However, further increase of the adsorbent dosage did not affect the removal rate. It may be because of the relatively low concentration of the solution during the reaction process, which could not be effectively combined with the adsorbent sites. Hence, to ensure the unit adsorption amounts and removal rates of the two pesticides simultaneously while saving costs, the BCF600 dosage was $0.75 \mathrm{~g} \mathrm{~L}^{-1}$, and the condition was used for the following experiments. In Figure 3, Teb represented tebuconazole, and Lin stood for linuron.

The setting of the stirring speed also had a great influence on the adsorption efficacy. Too low of the rotation rate of the shaker will cause the biochar to precipitate on the bottom of the conical flask, and the adsorption sites on its surface cannot make sufficient contact with the adsorbed substances. However, too high of the rotation rate will lead to the wastage of resources, and hence, the shaker rotation rate was taken into account to optimize the experimental conditions. The effect of agitation speed on the adsorption of two pesticides by BCF600 is shown in Figure 4. The adsorption capacity of biochar for both pesticides showed an increasing trend from the agitation speed growth and tended to equilibrium after $180 \mathrm{rmin}^{-1}$. Compared with $90 \mathrm{rmin}^{-1}$, the removal efficiency of tebuconazole and linuron was improved by $19.48 \%$ and $26.90 \%$, respectively, at $180 \mathrm{rmin}^{-1}$, and hence, $180 \mathrm{rmin}^{-1}$ was chosen as the agitation speed condition for the subsequent experiments.

3.1.3. Effect of Temperature. The effect of temperature on the adsorption of two pesticides by BCF600 is shown in Figure 3. The biochar sorption for both pesticides increased with an increase in the temperature. From the temperature perspective, the increased temperature directly results in a corresponding increase in the removal rate and unit adsorption amount. It may be attributed to the increase of surface activity and the effective active center of the adsorbent [69]. Therefore, the increase of temperature could promote the adsorption of tebuconazole and linuron in an aqueous solution. 
TABLE 1: Adsorption isotherm and kinetic models used in this paper.

\begin{tabular}{lcc}
\hline & Names & Equations \\
\hline \multirow{3}{*}{ Isotherm models } & Langmuir & $q_{e}=\left(q_{m} K_{L} C_{e} / 1+K_{L} C_{e}\right)$ \\
& Freundlich & $q_{e}=K_{f} C_{e}^{1 / n}$ \\
& Sips & $q_{e}=\left(K_{s} C_{e}\right)^{m} /\left(1+K_{s} C_{e}\right)^{m}$ \\
\hline \multirow{3}{*}{ Kinetic models } & Pseudo-first order & $q_{t}=q_{e}\left(1-\exp \left(-K_{1} t\right)\right)$ \\
& Pseudo-second order & $q_{t}=K_{2} q_{e} t\left(1+K_{2} q_{e} t\right)$ \\
& Elovich & $q_{t}=(1 / b) \ln a b+(1 / b) \ln t, t_{0}=1 / a b$ \\
\hline
\end{tabular}

Source: $[66,67]$.

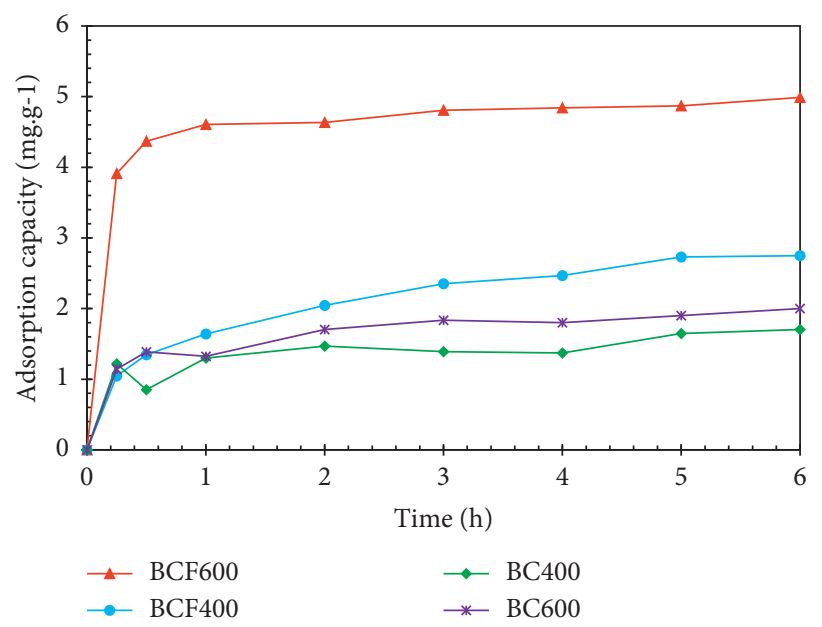

(a)

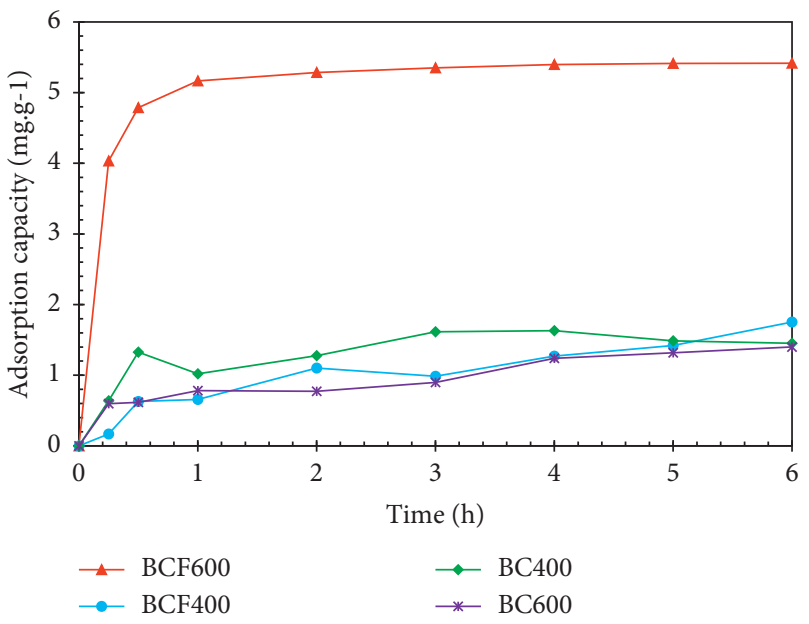

(b)

FIGURE 2: Comparison of the adsorption effect of biochar prepared under different conditions on tebuconazole (a) and linuron (b). Solution concentration: $5 \mathrm{mg} / \mathrm{L}$.

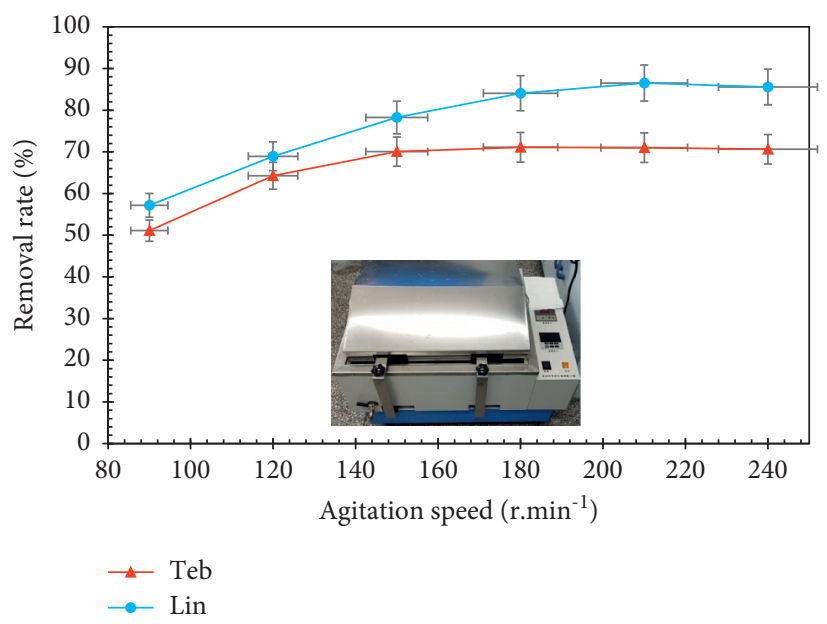

FIGURE 3: The effect of agitation speed on the adsorption of tebuconazole and linuron on BCF600. Solution concentration: $10 \mathrm{mg} / \mathrm{L}$.

3.1.4. Effect of Solution pH. The adsorption amount of tebuconazole and linuron is plotted against the initial $\mathrm{pH}$ of the solution in Figure 5. The effect of $\mathrm{pH}$ on the sorption of tebuconazole and linuron on BCF600 exhibits a different tendency in the $\mathrm{pH}$ range ( $\mathrm{pH} 3-10)$. For tebuconazole, the variation of the adsorption capacity in a series of different
$\mathrm{pH}$ values of the solutions showed that the $\mathrm{pH}$ value had a significant effect on the tebuconazole adsorption capacity of the biochars. The adsorption capacity of tebuconazole gradually dropped from $12.37 \mathrm{mg} \mathrm{g}^{-1}$ to $11.36 \mathrm{mg} \mathrm{g}^{-1}$ as the initial $\mathrm{pH}$ of the solution increased from 3 to 10 . Thus, the $\mathrm{pH}=3$ was the optimum experiment condition on 


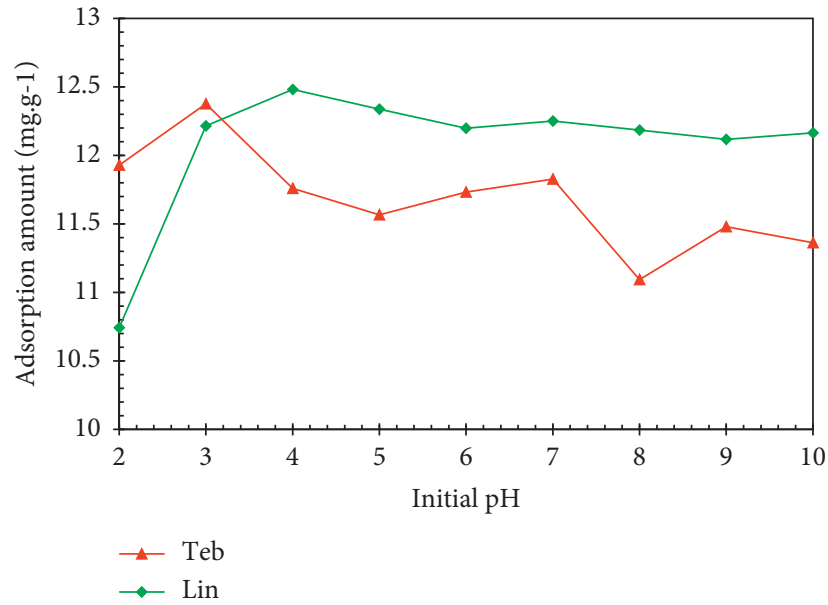

(a)

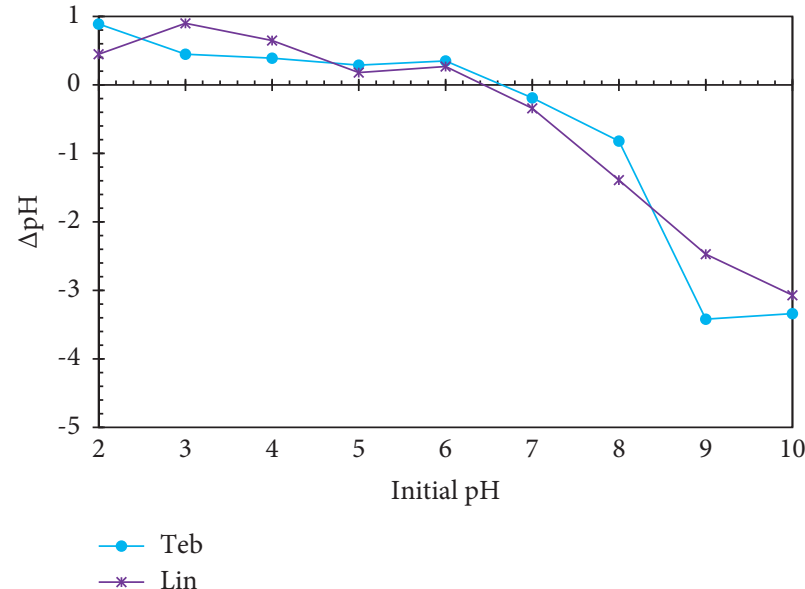

(b)

FIGURE 4: Effect of the initial solution pH on tebuconazole and linuron sorption capacities in BCF600 (a) and pH changes (b) of solution after equilibrium. Solution concentration: $10 \mathrm{mg} / \mathrm{L}$.

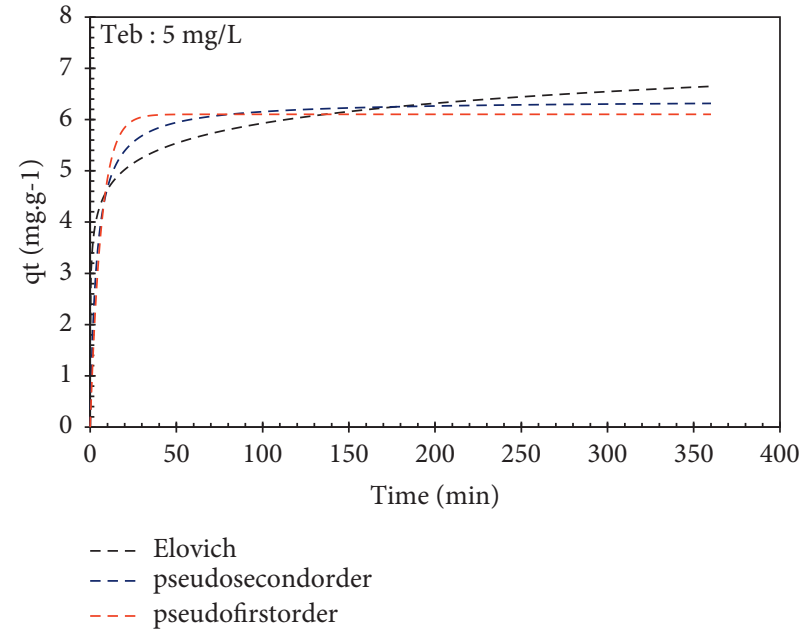

(a)

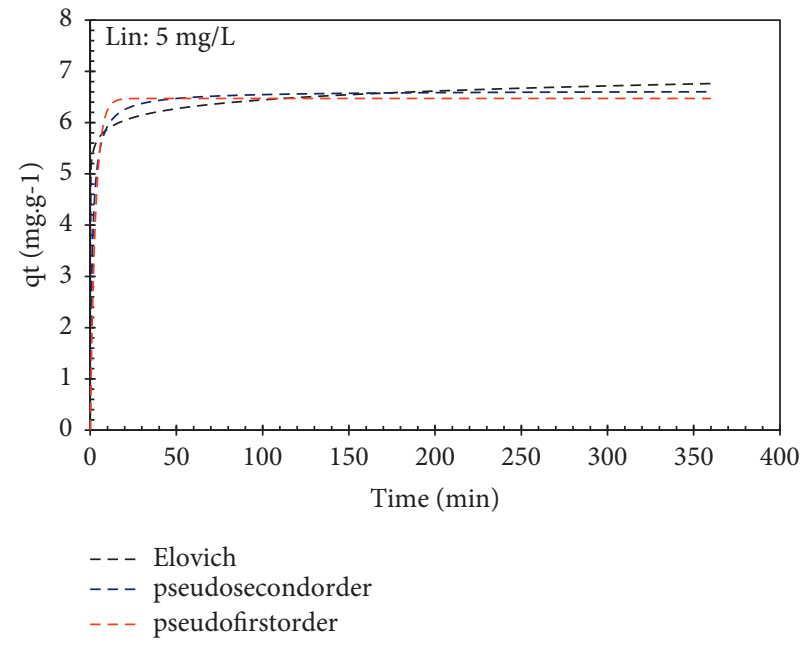

(c)

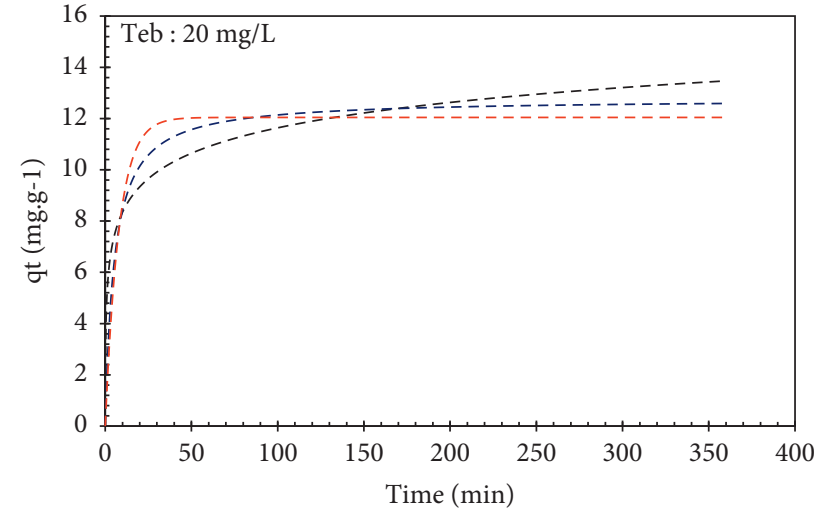

--- Elovich

- - - pseudosecondorder

- - - pseudofirstorder

(b)

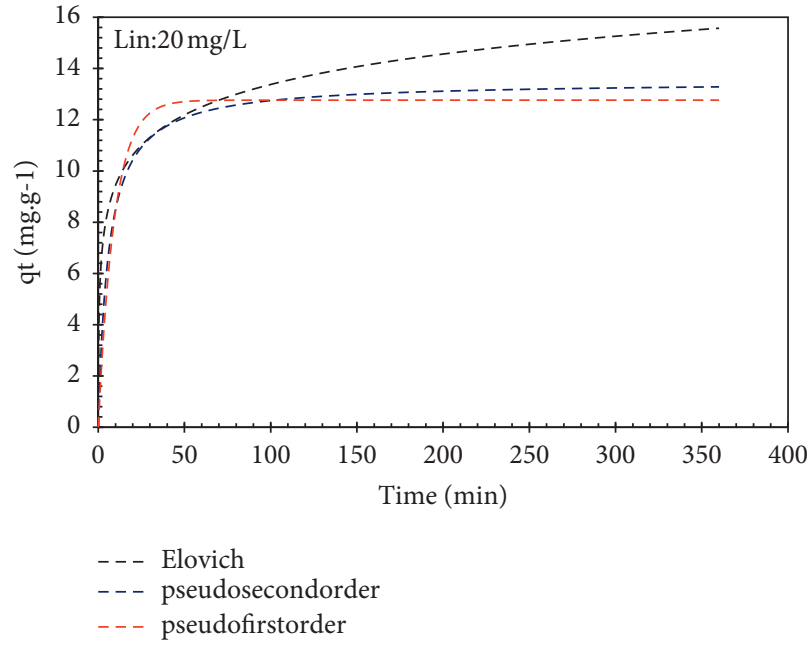

(d)

Figure 5: The kinetics and adsorption isotherms for tebuconazole and linuron adsorbed by BCF600. (a) Tebuconazole kinetics 5 mg/L, (b) tebuconazole kinetics $20 \mathrm{mg} / \mathrm{L}$, (c) linuron kinetics $5 \mathrm{mg} / \mathrm{L}$, and (d) linuron kinetics $20 \mathrm{mg} / \mathrm{L}$. 
tebuconazole removal, and the above evidence indicated that the adsorption of BCF600 for tebuconazole was favored by a low $\mathrm{pH}$. The results were primarily caused by the charge force interaction between the biochar and the adsorbate in an aqueous solution. The biochar mainly existed in a protonated form in the acidic aqueous solutions, while in a deprotonated form in the alkaline aqueous solutions. When the solution $\mathrm{pH}$ was greater than the $\mathrm{pK}_{\mathrm{a}}$ value of tebuconazole $\left(\mathrm{pK}_{\mathrm{a}}=5.03\right)$ [70], the tebuconazole molecules were negatively charged in the form of anions that would repel the negative charge on the surface of biochar and hinder the adsorption process. When the solution $\mathrm{pH}$ was less than the tebuconazole $\mathrm{pK}_{\mathrm{a}}$ value, most tebuconazole molecules existed in the molecular state, and the entire tebuconazole molecule would be positively charged under acidic conditions because of the presence of the lone pair of electrons on the $\mathrm{N}$ atom and facilitate the adsorption reaction. However, the variation of the $\mathrm{pH}$ value from 3-10 did not affect the adsorption amount of BCF600 to linuron. The experimental results were similar to D. Chaara [71]. This may be because of the higher $\mathrm{pK}_{\mathrm{a}}(12.13 \pm 0.70)$ of linuron compared to tebuconazole. The changes in the adsorption capacity of BCF600 for linuron may be observed in more alkaline aqueous solutions. It is worth noting that the adsorption capacity of linuron reached the lowest in the extremely acidic aqueous environment $(\mathrm{pH}=2)$. Meanwhile, compared with $\mathrm{pH}=3$, the adsorption capacity of tebuconazole also showed a slight decrease, which were not reported in previous studies.

By comparing the initial $\mathrm{pH}$ and the $\mathrm{pH}$ at the equilibrium of the solution, the biochar exhibited some ability to regulate the acid-base property of the aqueous solutions. At $\mathrm{pH}$ less than 5, the solution $\mathrm{pH}$ after the reaction, although not very pronounced, the solution showed a tendency to transition to basicity. At the $\mathrm{pH}$ greater than 5 or even in the alkaline environment $(\mathrm{pH}=10)$, the solution $\mathrm{pH}$ after the reaction all lied in the range of 6.27-6.97. The above evidence indicated that for the alkaline environmental water bodies, the biochar had a certain capacity for remediation regulation.

3.1.5. Effect of Salt Ions and Organic Matters. The metal salt ions affected the sorption of tebuconazole and linuron differently. The addition of metal salt ions did not significantly accelerate or decrease the reaction equilibrium time on the whole. As seen in Figure 4, $\mathrm{Pb}^{2+}$ enhanced the adsorption of tebuconazole to BCF600 at all pH concentrations. $\mathrm{K}^{+}$exhibited a clear promoting effect at low concentrations, and this phenomenon was similarly found for $\mathrm{Mg}^{2+}$ ions. A correlational analysis indicated that there was a negative correlation between $\mathrm{Cr}^{6+}$ and the sorption amount of tebuconazole $\left(r=-0.793^{* *}\right)$, and $\mathrm{Pb}^{2+}$ showed a significant positive relationship $\left(r=-0.700^{*}\right)$. As for linuron, $\mathrm{Mg}^{2+}, \mathrm{Pb}^{2+}, \mathrm{Cu}^{2+}$, and $\mathrm{K}^{+}$, upon lower treatments, enhanced the adsorption amount of linuron, whereas the higher treatments inhibited the same. Identical to tebuconazole, a negative correlation was found on $\mathrm{Cr}^{6+}$ $\left(r=-0.943^{* *}\right) . \mathrm{Ca}^{2+}$ enhanced the adsorption of linuron to
BCF600 at all pH concentrations with the Pearson correlation coefficient of $0.586^{*}$. The above phenomena were likely to be explained by the different action mechanisms of the cations versus the adsorbents. The metal salt ion $\left(\mathrm{Cr}^{6+}\right)$ showed a stronger ability to compete for the surface binding sites to inhibit the adsorption of tebuconazole and linuron. Meanwhile, the $\mathrm{C}-\mathrm{OH}$ functional group on tebuconazole and the $\mathrm{C}-\mathrm{N}$ functional group on linuron may form complexes with partial metal ions as illustrated in tetracycline molecules before, and to some extent, promote the adsorption of tebuconazole and linuron on BCF600 [72].

Humic acid was a kind of organic matter widely found in natural water bodies, and the typical value in natural surface water was approximately $2.50 \mathrm{mg} \mathrm{L}^{-1}$ [73]. Soluble starch was used to simulate the polysaccharide substances in real water bodies. Previous studies have shown that the presence of humic acids in aqueous solutions could lead to the formation of complexes with pollutants such as heavy metals or antibiotics and then be adsorbed by the biochar, thus enhancing the removal effect [74, 75]. As illustrated in Figure 4(b), the presence of humic acids was found to severely inhibit tebuconazole and linuron sorption on the BCF600 surface, and the soluble starch showed only a slight inhibitory effect with increasing concentration. The results showed that the concentrations of humic acids were significantly negatively correlated with the biochar sorption for both pesticides with the $r$ value of $-0.798^{* *}$ (tebuconazole) and $-0.947^{* *}$ (linuron), respectively. Several reasons might account for this phenomenon. One reason was that humic acids competed with the pesticides for the limited sorption sites on the biochar and reduced the chemisorption amount. The second reason was that a thin film could be coated on BCF600 surface by the humic acid, decreasing the specific surface area of BCF600 and affecting the physisorption ability, such as pore filling process, etc. [75]. The soluble starch exhibited a negative correlation only when it came to linuron.

The real water bodies represent the typical scenario when the real filed applications were used for the adsorption tests, and the results showed that in the real water samples, the removal of pesticides generally decreased by $10 \%$, depending on the nitrogen content in the water bodies. This phenomenon is also corroborated the above analysis (see Figure 6).

3.1.6. Kinetic Studies. The adsorption kinetic models are usually used to roughly estimate the adsorption rate and provide partial support for the interpretation of adsorption mechanism. The experimental data of tebuconazole and linuron removal for $360 \mathrm{~min}$ and the fitting parameters are shown in Table 2 and Figure 5. It is observed that the sorption process of the two pesticides by BCF600 was relatively quick, which was consistent with Grégorio Crini (2017) [76]. After $120 \mathrm{~min}$, there were no obvious differences between $180 \mathrm{~min}$ and $360 \mathrm{~min}$, and therefore, $180 \mathrm{~min}$ was considered to be a sufficient equilibrium time for tebuconazole and linuron to be adsorbed onto BCF600. This 


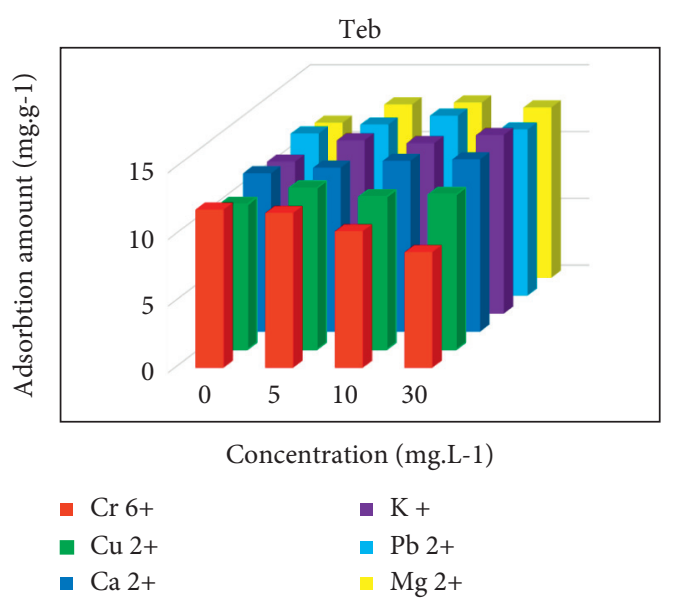

(a)

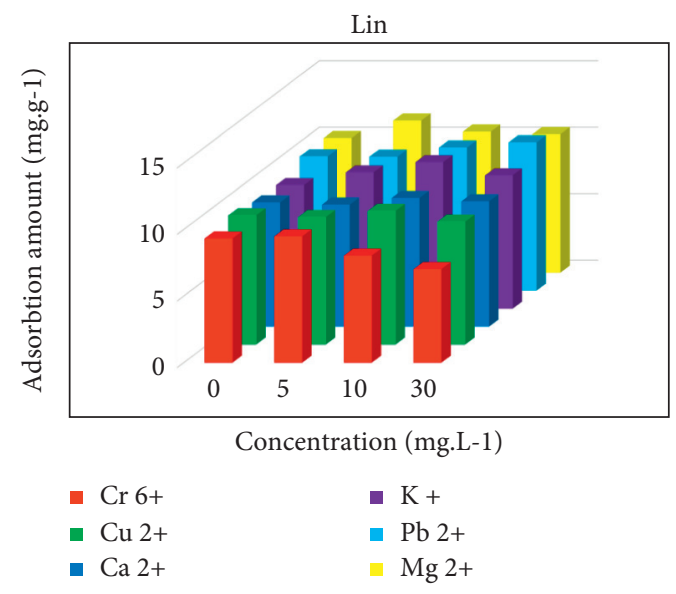

(b)

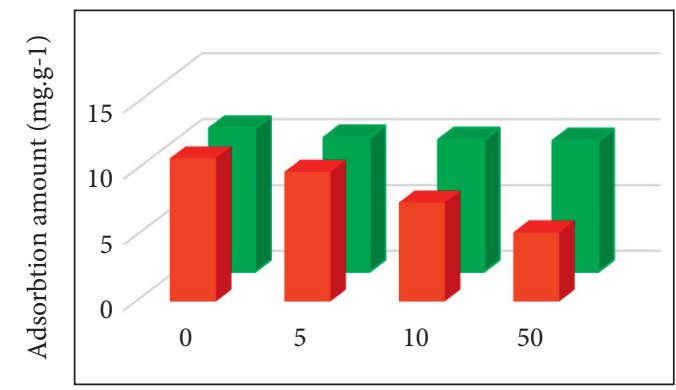

Concentration (mg.L-1)

- Humic acid

- Soluble starch

(c)

FIGURE 6: Effect of salt ions and organic matters on (a) tebuconazole (b) and linuron sorption capacities in BCF600, and (c) effect of organic matters on sorption capacities in BCF600.

TABLE 2: The model parameters and the corresponding correlation coefficient of the kinetic models.

\begin{tabular}{ccccccccccc}
\hline & & \multicolumn{3}{c}{ Pseudo-first order } & \multicolumn{3}{c}{ Pseudo-second order } & \multicolumn{3}{c}{ Elovich } \\
& $C_{0}\left(\mathrm{mg} \cdot \mathrm{L}^{-1}\right)$ & $q_{\mathrm{e}}\left(\mathrm{mg} \cdot \mathrm{g}^{-1}\right)$ & $K_{1}\left(\mathrm{~min}^{-1}\right)$ & $R^{2}$ & $q_{\mathrm{e}}\left(\mathrm{mg} \cdot \mathrm{g}^{-1}\right)$ & $K_{2}\left(\mathrm{~g} \cdot \mathrm{mg}^{-1} \cdot \mathrm{h}^{-1}\right)$ & $R^{2}$ & $a$ & $b$ & $R^{2}$ \\
\hline \multirow{2}{*}{ Teb } & 5 & 6.1024 & 0.1573 & 0.9488 & 6.3800 & 0.042 & 0.9885 & 213.2572 & 1.7784 & 0.9837 \\
& 20 & 12.0440 & 0.1269 & 0.8479 & 12.7707 & 0.015 & 0.9320 & 48.6464 & 0.6987 & 0.9853 \\
\hline \multirow{2}{*}{ Lin } & 5 & 4.8532 & 0.3331 & 0.9889 & 4.9676 & 0.1707 & 0.9940 & $3.49 * 108$ & 5.3708 & 0.9940 \\
& 20 & 12.7641 & 0.1077 & 0.8321 & 13.5000 & 0.0125 & 0.9150 & 41.9666 & 0.5834 & 0.9575 \\
\hline
\end{tabular}

equilibrium time was longer than the equilibrium time of tebuconazole adsorbed onto a corn straw biochar (less than $60 \mathrm{~min})$.

For tebuconazole, the value of the pseudo-second-order model $\left(R^{2}\right)$ was higher than that of the pseudo-first-order model, and the experimental values $6.4047 \mathrm{mgg}^{-1}$ $\left(C_{0}=5 \mathrm{mg} \mathrm{L}^{-1}\right)$ and $13.4748 \mathrm{mgg}^{-1} \quad\left(C_{0}=20 \mathrm{mg} \mathrm{L}^{-1}\right)$ of equilibrium adsorption capacity were closer with the theoretical values $\left(6.3800 \mathrm{mg} \mathrm{g}^{-1}\right.$ and $\left.12.7707 \mathrm{mg} \mathrm{g}^{-1}\right)$, respectively. Notably, the decrease in the value of the pseudo-firstorder model $\left(R^{2}\right)$ was evident with an increase in the initial concentration of tebuconazole. It might be indicating that at low concentrations, it was the result of a combination of physical and chemical effects, and at high concentrations, the physisorption was already saturated, and subsequently, it was dominated by chemisorption. The same trend was also found in the adsorption kinetic data for linuron. The Elovich model was also used for simulating the adsorption kinetics of tebuconazole and linuron to BCF600. The Elovich model was mainly used to describe the chemical adsorption and energy heterogeneity [77]. At different concentrations, the Elovich model showed a good fit for the adsorption process of both pesticides.

3.1.7. Adsorption Isotherms Studies. Langmuir, Freundlich, and Sips adsorption models were used to simulate the adsorption isotherms, and the fitting parameters results are shown in Table 3 and Figure 6. The actual results for tebuconazole can be described well with the Langmuir, 
TABLE 3: The model parameters and the corresponding correlation coefficient of adsorption isotherm models.

\begin{tabular}{ccccccccccccc}
\hline & & \multicolumn{3}{c}{ Langmuir } & \multicolumn{3}{c}{ Freundlich } & \multicolumn{4}{c}{ Sips } \\
& Temperature $\left({ }^{\circ} \mathrm{C}\right)$ & $q_{\mathrm{m}}\left(\mathrm{mg} \cdot \mathrm{g}^{-1}\right)$ & $K_{\mathrm{L}}\left(\mathrm{L} \cdot \mathrm{mg}^{-1}\right)$ & $R^{2}$ & $K_{\mathrm{f}}\left(\mathrm{mg}^{1-\mathrm{n}} \cdot \mathrm{g}^{-1} \mathrm{~L}^{-\mathrm{n}}\right)$ & $1 / n$ & $R^{2}$ & $K_{\mathrm{s}}$ & $R^{2}$ \\
\hline \multirow{3}{*}{ Teb } & 25 & 7.8650 & 0.2084 & 0.9581 & 6.6068 & 0.2661 & 0.9926 & 0.4238 & 0.3857 & 0.9976 \\
& 35 & 10.4060 & 0.2425 & 0.9698 & 6.9086 & 0.3696 & 0.9760 & 1.2022 & 0.5101 & 0.9955 \\
& 45 & 11.3094 & 0.6951 & 0.9283 & 8.2645 & 0.3403 & 0.9479 & 0.2335 & 0.4824 & 0.9503 \\
\hline \multirow{3}{*}{ Lin } & 25 & 9.0645 & 0.4214 & 0.9158 & 7.7967 & 0.3273 & 0.7937 & 14.59211 & 1.2833 & 0.9162 \\
& 35 & 13.7053 & 0.4493 & 0.9716 & 14.5612 & 0.2825 & 0.8330 & 33.9130 & 1.0088 & 0.9686 \\
& 45 & 17.2736 & 0.8099 & 0.9191 & 17.0678 & 0.4337 & 0.8483 & 27.9136 & 1.4618 & 0.9264 \\
\hline
\end{tabular}

Freundlich, and Sips models $\left(R^{2}>0.9200\right)$. Conclusively, the tebuconazole adsorption can be measured for monolayer and multilayers simultaneously. The Freundlich model provided a better fit, and the values of the correlation coefficient $R^{2}$ under the temperatures of $25^{\circ} \mathrm{C}, 35^{\circ} \mathrm{C}$, and $45^{\circ} \mathrm{C}$ were $0.9926,0.9760$, and 0.9479 , respectively. In addition, $n$ in the Freundlich model represents adsorption performance. When $0.1<1 / n<0.5$, it means that the adsorption reaction is favorable. When $1 / n>2$, it means that the adsorption is difficult to occur. At the three experimental temperatures, the $1 / n$ value is less than 0.5 , indicating that the tebuconazole adsorption reaction is prone to occur in aqueous environments. The Sips model is closer to the Langmuir model when the constant $m$ is closer to 1 and changes to the Freundlich model when $m$ is far from 1 . The data below showed that the $m$ values were between 0.3857 and 0.5101 , which indicated that the Freundlich model was more suitable for tebuconazole adsorption process; the Sips model also confirmed the above view.

According to the correlation coefficient $\left(R^{2}\right)$, unlike the tebuconazole adsorption process, the Langmuir model showed a better fitting compared with the Freundlich model, which indicated that the linuron adsorption process could be interpreted by the Langmuir model, and the maximum adsorption amount $\left(q_{\mathrm{m}}\right)$ was about $17.0678 \mathrm{mg} \mathrm{g}^{-1}$ at $45^{\circ} \mathrm{C}$. In addition, the $K_{\mathrm{L}}$ value of the three temperatures in linuron adsorption are in the range from 0.4214 to $0.8099 \mathrm{~L} \mathrm{mg}^{-1}$, suggesting that the adsorption between linuron and BCF600 is favorable. Meanwhile, the constant $m$ of the Sips model is close to 1 . These results suggested that BCF600 surface had uniform linuron adsorption sites. Meanwhile, the adsorption reaction mainly occurred on monolayers.

\section{Characterization of Biochar}

Two kinds of biochar: BC600 and BCF600 were subjected to SEM-EDX analysis to examine the morphology and components of the biochar surface, and the observation results are shown in Figure 7. The surface structure of BC600 was relatively smooth. Some embedded irregular cylindrical objects (marked in color), which are the compounds of iron, appeared obviously on the surface of the biochar after magnetization modification. It increased the roughness and specific surface area of the biochar, which were very important properties for the absorbent materials [78].

The FTIR spectra of BC600, BCF600, and BCF600 after tebuconazole and linuron adsorption are shown in Figure $8(\mathrm{a})$. The broad bands at $3412 \mathrm{~cm}^{-1}$ and $3409 \mathrm{~cm}^{-1}$ were attributed to the stretching vibration of the $-\mathrm{OH}$ functional groups, including the hydrogen bonding adsorbed on water or the water in the interlayer structure and the stretching vibration peak of $\mathrm{N}-\mathrm{H}$ [79]. The absorption peak at $1566 \mathrm{~cm}^{-1}$ was assigned to the stretching vibration of $C=\mathrm{O}$ of the alkenes, ketones, and aromatic compounds; the absorption peak at $1421 \mathrm{~cm}^{-1}$ was assigned to the $\mathrm{C}-\mathrm{H}$ deformation vibration and the backbone stretching vibration of the aromatic ring; the absorption peak at $1045 \mathrm{~cm}^{-1}$ was the asymmetric stretching vibration of $\mathrm{Si}-\mathrm{O}-\mathrm{Si}[80,81]$. The absorption peak at $873 \mathrm{~cm}^{-1}$ resulted from C-O nonplanar deformation, and the absorption peaks at $797 \mathrm{~cm}^{-1}$ and $710 \mathrm{~cm}^{-1}$ were the $\mathrm{C}-\mathrm{H}$ in-plane bending vibration in the aromatic rings. Finally, the absorption peak around $500 \mathrm{~cm}$ 1 was the ascribed vibration of the inorganic groups such as $\mathrm{CO}_{3}{ }^{2-}, \mathrm{PO}_{4}{ }^{2-}$, and $\mathrm{SiO}_{4}{ }^{2-}$ formed by the retention of inorganic elements in the sludge biochar during pyrolysis. After modification, a new absorption peak generated at $1614 \mathrm{~cm}^{-1}$, and the absorption peaks at $1421 \mathrm{~cm}^{-1}$ disappeared. The above changes may be related to the characteristic absorption peaks of $\mathrm{Fe}-\mathrm{O}-\mathrm{C}(\mathrm{O})$, indicating that the carboxylic acid and $\mathrm{C}-\mathrm{H}$ groups in the sludge were successfully combined with the iron atom. Meanwhile, several vibration peaks from $500-1000 \mathrm{~cm}^{-1}$ changed and partially weakened. The reason for this phenomenon may be that the ferric oxides were successfully introduced to BCF600 [82, 83].

After tebuconazole and linuron uptake, the carboxyl vibration peak at $1614 \mathrm{~cm}^{-1}$ shifted to $1600 \mathrm{~cm}^{-1}$ and $1597 \mathrm{~cm}^{-1}$, respectively, indicating that tebuconazole and linuron had an effect on the structure of carboxyl groups, thus producing a chemisorption reaction. The peak at $1048 \mathrm{~cm}^{-1}$ shifted to $1045 \mathrm{~cm}^{-1}$ and $1041 \mathrm{~cm}^{-1}$, which suggested that $\mathrm{Si}-\mathrm{O}-\mathrm{Si}$ groups may participate in the adsorption process. Except for that, there were no obvious absorption peaks that disappeared or new absorption peaks that generated, which implied that a large number of physisorption interactions existed between the biochar and the two pesticides. It did not change the host structure of the biochar after sorption.

The porous structure of BC600/BCF600 was identified by the $\mathrm{N}_{2}$ sorption isotherms (Figure $7(\mathrm{~b})$ ). According to the IUPAC classification standard, the $\mathrm{N}_{2}$ sorption isotherms on the two biochars belong to type IV because the curves of the sorption isotherm and the desorption isotherm do not coincide with each other to form a hysteresis loop [84]. The BET surface area and the Langmuir surface area of the pyrolyzed BCF600 are $79.2445 \mathrm{~m}^{2} / \mathrm{g}$ and $204.4121 \mathrm{~m}^{2} / \mathrm{g}$, 


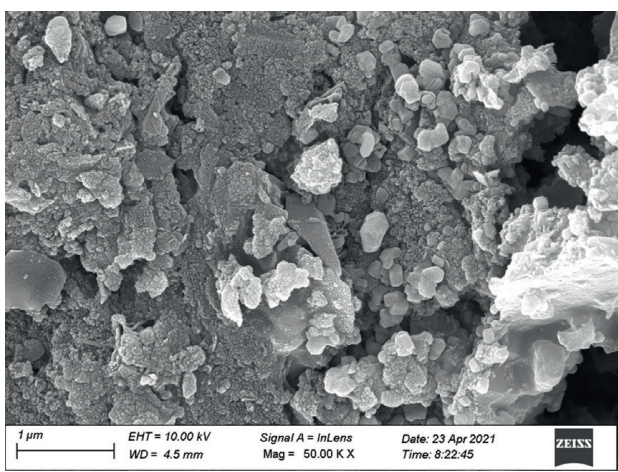

(a)

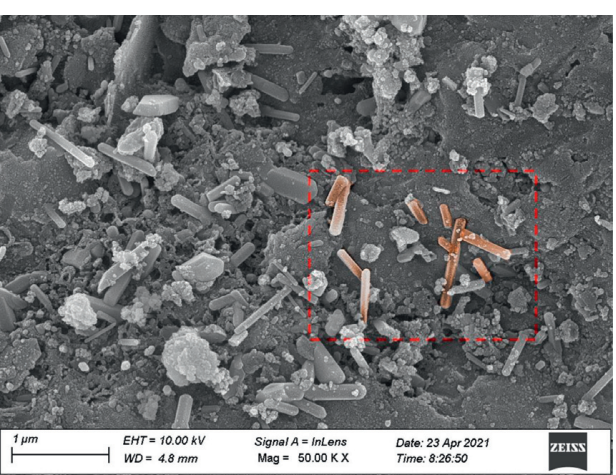

(b)

FIGURE 7: The SEM image of the biochar, including the EDX spectrum: (a) BC600 and (b) BCF600.

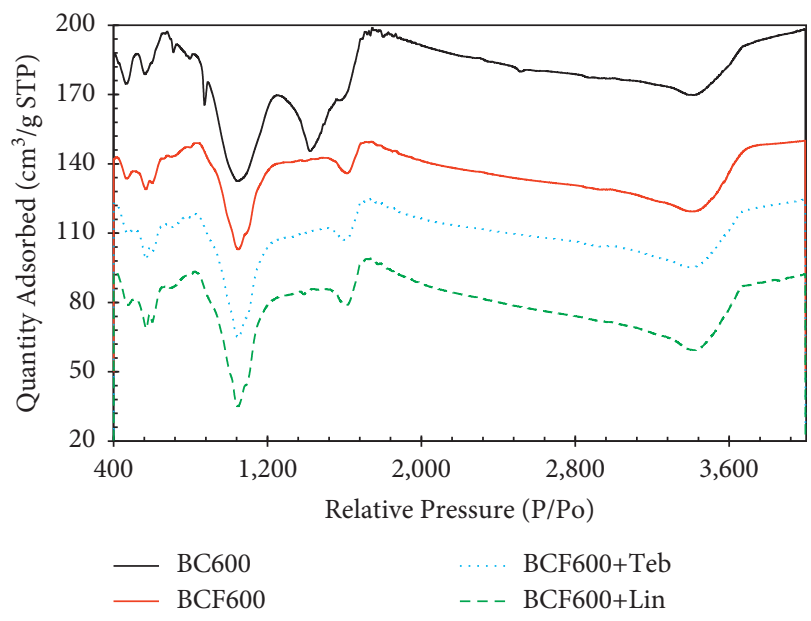

(a)

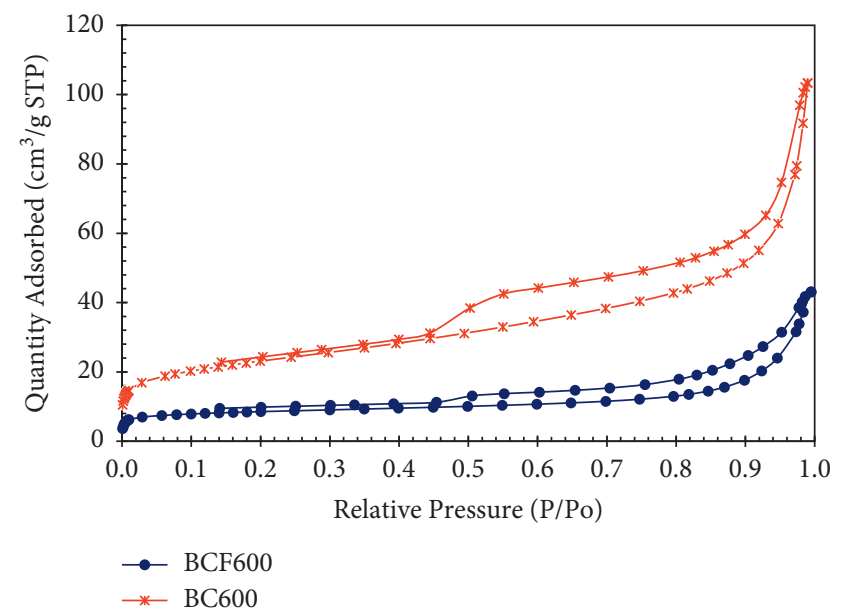

(b)

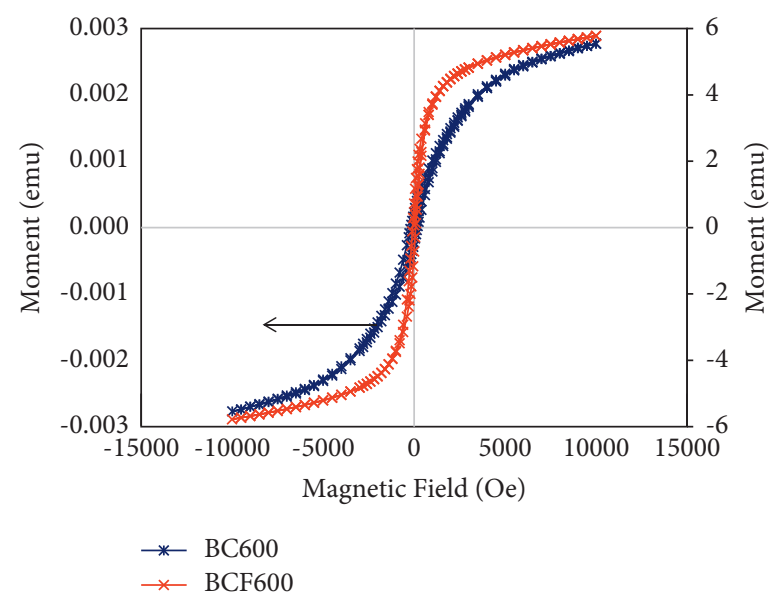

(c)

FIGURE 8: (a) FTIR spectrum of BC600, BCF600, and BCF600 adsorbed tebuconazole and linuron. (b) The isotherm of nitrogen in the sorption-desorption process for BC600 and BCF600. (c) Magnetic hysteresis loop of BC600 and BCF600.

respectively, while the two numerical values of BC600 are decreased to $28.6556 \mathrm{~m}^{2} / \mathrm{g}$ and $59.8426 \mathrm{~m}^{2} / \mathrm{g}$. BCF600 had a larger surface area and richer pores, and the micropore volume made up more than $8.5 \%$ of the total pore volume, which was much higher than that in BC600. The addition of
$\mathrm{FeCl}_{3}$ had obviously changed the surface properties of the biochar. The results of BET analysis and SEM observation were validated against each other, indicating that the surface morphology and adsorption properties of BCF600 were improved. 
TABLE 4: The adsorption properties of different materials for tebuconazole (Teb) and linuron (Lin): a comparison.

\begin{tabular}{|c|c|c|c|c|}
\hline Adsorbent materials & Raw materials & Initial $\mathrm{pH}$ & Adsorption capacity & Reference \\
\hline $\begin{array}{l}\text { Graphene } / \mathrm{Fe}_{3} \mathrm{O}_{4} \\
\text { nanocomposite }\end{array}$ & $\begin{array}{l}\mathrm{Fe}^{2+}, \mathrm{Fe}^{3+} \text { and } \\
\text { graphene }\end{array}$ & Unadjusted & $78.3 \mathrm{mg} / \mathrm{g}(\mathrm{Teb})$ & (Wang et al., 2019) [89] \\
\hline Biochar & Fruit shell & Unadjusted & $10.8 \mathrm{mg} / \mathrm{g}(\mathrm{teb})$ & (Xue et al., 2019) [90] \\
\hline Biochar & Corn straw & Unadjusted & $11.35 \mathrm{mg} / \mathrm{g}(\mathrm{teb})$ & (Sun et al., 2019) [91] \\
\hline Activated carbon & Spent coffee & 4.8 & $4.83 \mathrm{mg} / \mathrm{g}$ (lin) & (Ali hgeig et al., 2019) [92] \\
\hline Organohydrotalcites & Hydrotalcite & $8 \pm 0.5$ & $3.35 \mathrm{mg} / \mathrm{g}$ (lin) & $\begin{array}{c}\text { (D. Chaara et al., 2012) } \\
\text { [71] }\end{array}$ \\
\hline Biochar & Excess sludge & $\begin{array}{l}\text { 3(Teb) unadjusted } \\
\text { (lin) }\end{array}$ & $\begin{array}{c}12.37 \mathrm{mg} / \mathrm{g} \text { (teb) } 9.06 \mathrm{mg} / \mathrm{g} \\
\text { (lin) }\end{array}$ & This study \\
\hline
\end{tabular}

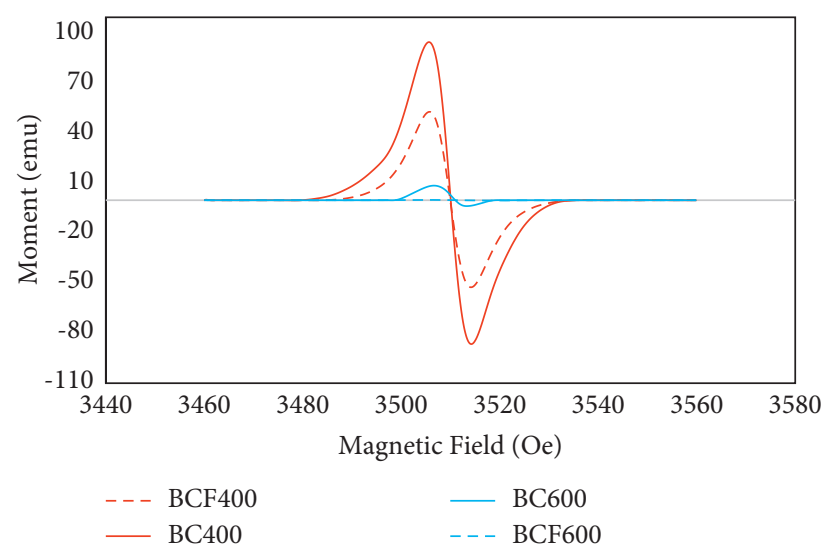

FIGURE 9: ESR spectra of BC400, BC600, BCF400, and BCF600.

To investigate the magnetic properties, a magnetic hysteresis curve for BC600 and BCF600 were recorded at $25{ }^{\circ} \mathrm{C}$ (Figure 8(c)). The samples showed the saturation magnetization of $0.0028 \mathrm{emu} / \mathrm{g}$ for the biochar and 5.7800 $\mathrm{emu} / \mathrm{g}$ for BCF600. Based on previous research, such a magnetization (5.7800) is sufficient to allow easy separation from water with a magnet, and the fact (Figure 8(c)) also proved this. This property is essentially important to improve the adsorption performance and recovery value of materials. However, XRD analysis (Figures S1-S5) indicated that no obvious characteristic peaks related to Fe element were found although the presence of ferric element was found in EDX and FTIR spectra (Tables S1-S4). It might be caused by the uneven distribution of Fe during the biochar modification process. This is similar to previous studies [85].

\section{Effect of Different Preparation Conditions on EPFRs Formation of Biochar and Leaching Experiments}

EPFRs are long-lived, stable, and persistent free radicals that are supposed to be a new class of environmental risk substances and exhibit paramagnetic stability. The half-life of EPFRs is relatively long because of the binding and synergy between the persistent free radicals on the surface of some particles, which reinforces the stability of these groups [86]. Previous studied have showed that EPFRs are mainly generated in the late stage of organic combustion, in the low temperature region of combustion, and during some other thermal treatments [87]. The paramagnetic properties of EPFRs arise from the unpaired electrons that can be detected using the electron paramagnetic resonance (EPR). The ESR spectra of the four absorbent materials are displayed in Figure 8. Compared with BC400 and BC600, as the pyrolysis temperature of the materials increases, the ESR signal weakens. Moreover, the biochar prepared at both temperatures after magnetization showed significantly lower free radical signals, which may be because of the effect of transition metals that hinder EPFRs' formation [88].

The value of the g-factor is an important spectral parameter to discern the types of EPFRs, and it is calculated using the following formula:

$$
g=\frac{h v}{\mu_{B} B},
$$

where $h$ represents Planck's constant $\left(6.626 \times 10^{-34} \mathrm{~J} \mathrm{~s}\right), v$ is the frequency $(\mathrm{GHz})$, and $\mu_{B}$ represents the Bohr magneton $\left(9.274 \times 10^{-24} \mathrm{~J} / \mathrm{T}\right)$. Meanwhile, $\mathrm{H}$ represents the intensity of the resonance magnetic field (Gauss), which was $3510 \mathrm{~T}$ in this study (see Table 4). It has been reported that the carboncentered radicals have g-factors $<2.0030$, the carbon-centered radicals with an adjacent oxygen atom have g-factors in the range 2.0030-2.0040, and the oxygen-centered radicals have g-factors $>2.0040$. The $g$-factors of BC400, BC600, BCF400, and BCF600 were 2.0036, 2.0035, 2.0035, and 2.0034, respectively. All the $g$-factors were between 2.0030 and 2.0040, which suggests that the EPFRs were predominantly carbon-centered radicals with an adjacent oxygen atom [93]. 
The leaching experiments were also carried out to evaluate whether the biochar caused secondary pollution. The results (Table S4) showed that of the six metal ions measured, all but iron and zinc were detected at $0.2025 \mathrm{mg} / \mathrm{L}$ and $0.03097 \mathrm{mg} / \mathrm{L}$ level at $100 \mathrm{ml}$ volume, respectively (see Figure 9). The source of the ferric ions was attributed to the weak binding of ferric chloride to the biochar fraction. However, the zinc ions, which may be contained by the raw materials themselves, failed to be gasified completely at high temperatures and resided inside the biochar. Thus, they precipitated into the aqueous solution during the reaction process. The concentrations of the two metal ions will not constitute secondary pollution [94].

\section{Conclusions}

Excess sludge derived biochar was magnetically modified using $\mathrm{FeCl}_{3} \bullet 6 \mathrm{H}_{2} \mathrm{O}$ as a precursor for adsorption. The magnetic biochar (BCF600) had a relatively higher specific surface $\left(79.2445 \mathrm{~m}^{2} / \mathrm{g}\right)$, which was nearly threefold that of BC600 $\left(28.6556 \mathrm{~m}^{2} / \mathrm{g}\right)$. The tebuconazole and linuron adsorption capacities were significantly improved compared to those of a common pyrolyzed biochar. The maximum tebuconazole and linuron adsorption capacities of BCF600 were $7.865 \mathrm{mgg}^{-1}$ and $9.064 \mathrm{mgg}^{-1}$, respectively. Under acidic conditions $(\mathrm{pH}=3)$, the adsorption amount of tebuconazole reached the maximum of $12.37 \mathrm{mg} \mathrm{g}^{-1}$, whereas linuron hardly changed with $\mathrm{pH}$. The adsorption experiments with the coexisting substances showed that some metal ions and organics exhibited obvious roles in promoting or inhibiting the adsorption, among which $\mathrm{Cr}^{6+}$ and humic acid significantly inhibited the adsorption of the two pesticides (with $r=-0.793^{* *}$ ). EPFRs preferred to form at lower pyrolysis temperature (BC400 had the strongest ESR signal). The $g$-factors were between 2.0030 and 2.0040, suggesting that the EPFRs were predominantly carboncentered radicals with an adjacent oxygen atom.

From the present findings, the magnetic biochar (BCF600) has a great potential for tebuconazole and linuron removal from aqueous environments without secondary contamination. It is an ideal channel for the resource reduction of waste-activated sludge. More regrettably, a large number of different organic-inorganic solvents have been tried in this paper, all of which failed to succeed in the reuse of the materials. Meanwhile, because of the different raw material sources, there may exist significant differences in its own physicochemical properties that may cause differences in the adsorption efficacy of the sludge-based biochars for tebuconazole and linuron. Whether this material can remove other contaminants simultaneously and efficiently remains to be verified.

\section{Data Availability}

No data were used to support this study.

\section{Conflicts of Interest}

The authors declare that they have no conflicts of interest.

\section{Acknowledgments}

This study was supported by the Natural Science Foundation of Shandong Province General Program (ZR2020ME226).

\section{Supplementary Materials}

Figure S1: tebuconazole and linuron particle morphologies. Figure S2: the adsorption effect of biochar prepared under different conditions on tebuconazole and linuron. Figure S3: effect of temperature on adsorption of tebuconazole and linuron on BCF600. Figure S4: tebuconazole and linuron removal efficacy in real water bodies on BCF600. Figure S5: XRD analysis of BC600, BCF600, and BCF600 after uptake tebuconazole and linuron. Table S1: correlational analysis of BCF600 adsorption capacity and concentration of metal salt ions: (a) tebuconazole and (b) linuron. Table S2: correlational analysis of BCF600 adsorption capacity and concentration of humic acid and soluble starch: (a) tebuconazole and (b) linuron. Table S3: water quality parameters at different sampling locations. Table S4: partial metal ion concentrations in supernatant: leaching experiments. (Supplementary Materials)

\section{References}

[1] S. Kreisig, A. Tarazona, and E. Koglin, "The adsorption of paraquat on silver electrode surfaces: a SERS microprobe study," Electrochimica Acta, vol. 42, no. 20-22, pp. 3335-3344, 1997.

[2] L. Zhang, Y. Xu, H. Liu et al., "Effects of coexisting Na+, Mg2+ and $\mathrm{Fe} 3+o n$ nitrogen and phosphorus removal and sludge properties using A2O process," Journal of Water Process Engineering, vol. 44, Article ID 102368, 2021.

[3] Z. Yang, Z. Lian, G. Liu et al., "Identification of genetic markers associated with milk production traits in Chinese Holstein cattle based on post genome-wide association studies," Animal Biotechnology, vol. 32, no. 1, pp. 67-76, 2021.

[4] W. Deng, K. Xu, Z. Xiong et al., "Evolution of aromatic structures during the low-temperature electrochemical upgrading of bio-oil," Energy \& Fuels, vol. 33, no. 11, pp. 11292-11301, 2019.

[5] S.-S. Yang, X.-L. Yu, M.-Q. Ding et al., "Simulating a combined lysis-cryptic and biological nitrogen removal system treating domestic wastewater at low $\mathrm{C} / \mathrm{N}$ ratios using artificial neural network," Water Research, vol. 189, Article ID 116576, 2021.

[6] Z. Lan, Y. Zhao, J. Zhang et al., "Long-term vegetation restoration increases deep soil carbon storage in the Northern Loess Plateau," Scientific Reports, vol. 11, no. 1, 2021.

[7] K. Tan, Y. Qin, T. Du, L. Li, L. Zhang, and J. Wang, "Biochar from waste biomass as hygroscopic filler for pervious concrete to improve evaporative cooling performance," Construction and Building Materials, vol. 287, Article ID 123078, 2021.

[8] H. Guan, S. Huang, J. Ding, F. Tian, Q. Xu, and J. Zhao, "Chemical environment and magnetic moment effects on point defect formations in CoCrNi-based concentrated solidsolution alloys," Acta Materialia, vol. 187, pp. 122-134, 2020.

[9] X. Ji, C. Hou, M. Shi, Y. Yan, and Y. Liu, "An insight into the research concerning panax ginseng C. A. Meyer polysaccharides: a review," Food Reviews International, pp. 1-17, 2020. 
[10] X. Ji, B. Peng, H. Ding, B. Cui, H. Nie, and Y. Yan, "Purification, structure and biological activity of pumpkin polysaccharides: a review," Food Reviews International, pp. 1-13, 2021.

[11] Q. Ul Ain, G. Rehman, and M. Zaheer, "An analysis of water flow in subsurface environment by using adomian decomposition method," Water Conservation and Management, vol. 3, no. 1, pp. 27-29, 2019.

[12] J. Ni, X. Zhuang, and M. Abdel Wahab, "Review on the prediction of residual stress in welded steel components," Computers, Materials \& Continua, vol. 62, no. 2, pp. 495-523, 2020.

[13] S. Kang and T. Park, "Detecting outlier behavior of game player players using multimodal physiology data," Intelligent Automation \& Soft Computing, vol. 26, no. 1, pp. 205-214, 2020.

[14] S. Kaur and V. K. Joshi, "Hybrid soft computing technique based trust evaluation protocol for wireless sensor networks," Intelligent Automation \& Soft Computing, vol. 26, no. 2, pp. 217-226, 2020.

[15] M. Sharma, H. Pham, and V. B. Singh, "Modeling and analysis of leftover issues and release time planning in multi-release open source software using entropy based measure," Computer Systems Science and Engineering, vol. 34, no. 1, pp. 33-46, 2019.

[16] S. Vengadeswaran and Balasundaram, "Core - an optimal data placement strategy in hadoop for data intentitive applications based on cohesion relation," Computer Systems Science and Engineering, vol. 34, no. 1, pp. 47-60, 2019.

[17] K. Li, W. Yang, and K. Li, "A hybrid parallel solving algorithm on GPU for quasi-tridiagonal system of linear equations," IEEE Transactions on Parallel and Distributed Systems, vol. 27, no. 10, pp. 2795-2808, 2016.

[18] K. Li, X. Tang, B. Veeravalli, and K. Li, "Scheduling precedence constrained stochastic tasks on heterogeneous cluster systems," IEEE Transactions on Computers, vol. 64, no. 1, pp. 191-204, 2015.

[19] W. Yang, K. Li, Z. Mo, and K. Li, "Performance optimization using partitioned SpMV on GPUs and multicore CPUs," IEEE Transactions on Computers, vol. 64, no. 9, pp. 2623-2636, 2015.

[20] T. Berglöf, T. Van Dung, H. Kylin, and I. Nilsson, "Carbendazim sorption-desorption in Vietnamese soils," Chemosphere, vol. 48, no. 3, pp. 267-273, 2002.

[21] J. Mei, K. Li, A. Ouyang, and K. Li, "A profit maximization scheme with guaranteed quality of service in cloud computing," IEEE Transactions on Computers, vol. 64, no. 11, pp. 3064-3078, 2015.

[22] K. Li, W. Yang, and K. Li, "Performance analysis and optimization for SpMV on GPU using probabilistic modeling," IEEE Transactions on Parallel and Distributed Systems, vol. 26, no. 1, pp. 196-205, 2015.

[23] K. Li, W. Ai, Z. Tang et al., "Hadoop recognition of biomedical named entity using conditional random fields," IEEE Transactions on Parallel and Distributed Systems, vol. 26, no. 11, pp. 3040-3051, 2015.

[24] Y. Xu, K. Li, L. He, L. Zhang, and K. Li, "A hybrid chemical reaction optimization scheme for task scheduling on heterogeneous computing systems," IEEE Transactions on Parallel and Distributed Systems, vol. 26, no. 12, pp. 3208-3222, 2015.

[25] K. Li, W. Zheng, and K. Li, "A fast algorithm with less operations for Length-N=q|times $2 \mathrm{~m}$ DFTs," IEEE Transactions on Signal Processing, vol. 63, no. 3, pp. 673-683, 2015.
[26] K. Li, X. Tang, and K. Li, "Energy-efficient stochastic task scheduling on heterogeneous computing systems," IEEE Transactions on Parallel and Distributed Systems, vol. 25, no. 11, pp. 2867-2876, 2014.

[27] A. Toolabi, M. Malakootian, M. T. Ghaneian et al., "Optimization of photochemical decomposition acetamiprid pesticide from aqueous solutions and effluent toxicity assessment by Pseudomonas aeruginosa BCRC using response surface methodology," AMB Express, vol. 7, no. 1, pp. 159-212, 2017.

[28] X. Tang, K. Li, Z. Zeng, and B. Veeravalli, "A novel securitydriven scheduling algorithm for precedence-constrained tasks in heterogeneous distributed systems," IEEE Transactions on Computers, vol. 60, no. 7, pp. 1017-1029, 2011.

[29] D. Zhang, X. Chen, F. Li, A. K. Sangaiah, and X. Ding, "Seamcarved image tampering detection based on the cooccurrence of adjacent LBPs," Security and Communication Networks, vol. 2020, Article ID 8830310, 2020.

[30] Y. Song, D. Zhang, Q. Tang, S. Tang, and K. Yang, "Local and nonlocal constraints for compressed sensing video and multiview image recovery," Neurocomputing, vol. 406, pp. 34-48, 2020.

[31] S. Zhou and J. Qiu, "Enhanced SSD with interactive multiscale attention features for object detection," Multimedia Tools and Applications, vol. 80, no. 8, pp. 11539-11556, 2021.

[32] Q. Tang, K. Wang, K. Yang, and Y.-S. Luo, "Congestionbalanced and welfare-maximized charging strategies for electric vehicles," IEEE Transactions on Parallel and Distributed Systems, vol. 31, no. 12, pp. 2882-2895, 2020.

[33] J. Wang, W. Chen, Y. Ren, O. Alfarraj, and L. Wang, "Blockchain based data storage mechanism in cyber physical system," Journal of Internet Technology, vol. 21, no. 6, pp. 1681-1689, 2020.

[34] Y. Song, J. Li, X. Chen, D. Zhang, Q. Tang, and K. Yang, “An efficient tensor completion method via truncated nuclear norm," Journal of Visual Communication and Image Representation, vol. 70, Article ID 102791, 2020.

[35] J. Wang, W. Wu, Z. Liao, Y. W. Jung, and J. U. Kim, “An enhanced PROMOT algorithm with D2D and robust for mobile edge computing," Journal of Internet Technology, vol. 21, no. 5, pp. 1437-1445, 2020.

[36] M. Komárek, E. Čadková, V. Chrastný, F. Bordas, and J. C. Bollinger, "Contamination of vineyard soils with fungicides: a review of environmental and toxicological aspects," Environment International, vol. 36, no. 1, pp. 138-151, 2010.

[37] A. Gonsioroski, V. E. Mourikes, and J. A. Flaws, "Endocrine disruptors in water and their effects on the reproductive system," International Journal of Molecular Sciences, vol. 21, no. 6, Article ID 1929, 2020.

[38] J. Wang, X. Chen, X. Sun et al., "Degradation pathway of triazole fungicides and synchronous removal of transformation products via photo-electrocatalytic oxidation tandem MoS2 adsorption," Environmental Science and Pollution Research, vol. 28, no. 13, pp. 16480-16491, 2021.

[39] D. Zhang, S. Wang, F. Li et al., "An efficient ECG denoising method based on empirical mode decomposition, sample entropy, and improved threshold function," Wireless Communications and Mobile Computing, vol. 2020, 2020.

[40] Q. Tang, K. Wang, Y. Song, F. Li, and J. H. Park, "Waiting time minimized charging and discharging strategy based on mobile edge computing supported by software-defined network," IEEE Internet of Things Journal, vol. 7, no. 7, pp. 6088-6101, 2019.

[41] J. Zhang, K. Yang, L. Xiang, Y. Luo, B. Xiong, and Q. Tang, “A self-adaptive regression-based multivariate data compression 
scheme with error bound in wireless sensor networks," International Journal of Distributed Sensor Networks, vol. 9, no. 3, Article ID 913497, 2013.

[42] J. Zhang, J. Sun, J. Wang, and X. G. Yue, "Visual object tracking based on residual network and cascaded correlation filters," Journal of Ambient Intelligence and Humanized Computing, vol. 12, pp. 8427-8440, 2020.

[43] K. Gu, Y. Wang, and S. Wen, "Traceable threshold proxy signature," Journal of Information Science and Engineering, vol. 33, no. 1, 2017.

[44] W. Li, Y. Ding, Y. Yang, R. S. Sherratt, J. H. Park, and J. Wang, "Parameterized algorithms of fundamental NP-hard problems: a survey," Human-Centric Computing and Information Sciences, vol. 10, no. 1, pp. 1-24, 2020.

[45] A. Ragab, I. Ahmed, and D. Bader, "The removal of brilliant green dye from aqueous solution using nano hydroxyapatite/ chitosan composite as a sorbent," Molecules, vol. 24, no. 5, Article ID 847, 2019.

[46] K. Gu, L. Yang, Y. Wang, and S. Wen, "Traceable identitybased group signature," RAIRO - Theoretical Informatics and Applications, vol. 50, no. 3, pp. 193-226, 2016.

[47] B. Yin, S. Zhou, Y. Lin, Y. Liu, and Y. Hu, "Efficient distributed skyline computation using dependency-based data partitioning," Journal of Systems and Software, vol. 93, pp. 69-83, 2014.

[48] M. Long and X. Xiao, "Outage performance of double-relay cooperative transmission network with energy harvesting," Physical Communication, vol. 29, pp. 261-267, 2018.

[49] Z. Xu, W. Liang, K.-C. Li, J. Xu, and H. Jin, “A blockchainbased roadside unit-assisted authentication and key agreement protocol for internet of vehicles," Journal of Parallel and Distributed Computing, vol. 149, pp. 29-39, 2021.

[50] W. Wang, Y. Yang, J. Li, Y. Hu, Y. Luo, and X. Wang, "Woodland labeling in chenzhou, China, via deep learning approach," International Journal of Computational Intelligence Systems, vol. 13, no. 1, pp. 1393-1403, 2020.

[51] Y. Qu and N. Xiong, "RFH: A resilient, fault-tolerant and high-efficient replication algorithm for distributed cloud storage," in Proceedings of the The 41st International Conference on Parallel Processing, pp. 520-529, Pittsburgh, PA, USA, September 2012.

[52] L. Lou, L. Yao, G. Cheng, L. Wang, Y. He, and B. Hu, "Application of rice-straw biochar and microorganisms in nonylphenol remediation: adsorption-biodegradation coupling relationship and mechanism," PloS one, vol. 10, no. 9, Article ID e0137467, 2015.

[53] W. Fang, X. Yao, X. Zhao, J. Yin, and N. Xiong, “A stochastic control approach to maximize profit on service provisioning for mobile cloudlet platforms," IEEE Transactions on Systems, Man, and Cybernetics: Systems, vol. 48, no. 4, pp. 522-534, 2016.

[54] J. Luo, X. Li, C. Ge et al., "Sorption of norfloxacin, sulfamerazine and oxytetracycline by $\mathrm{KOH}$-modified biochar under single and ternary systems," Bioresource Technology, vol. 263, pp. 385-392, 2018.

[55] M. Han, J. Zhang, W. Chu, G. Zhou, and J. Chen, "Surfacemodified sewage sludge-derived carbonaceous catalyst as a persulfate activator for phenol degradation," International Journal of Environmental Research and Public Health, vol. 17, no. 9, Article ID 3286, 2020.

[56] M. Zhang, B. Gao, S. Varnoosfaderani, A. Hebard, Y. Yao, and M. Inyang, "Preparation and characterization of a novel magnetic biochar for arsenic removal," Bioresource Technology, vol. 130, pp. 457-462, 2013.
[57] T. Zhao, R. Chen, and J. Wang, "A mild method for preparation of highly selective magnetic biochar microspheres," International Journal of Molecular Sciences, vol. 21, no. 11, Article ID 3752, 2020.

[58] M. Ahmad, M. A. Akanji, A. R. A. Usman, A. S. F. Al-Farraj, Y. F. Tsang, and M. I. Al-Wabel, "Turning date palm waste into carbon nanodots and nano zerovalent iron composites for excellent removal of methylthioninium chloride from water," Scientific Reports, vol. 10, no. 1, pp. 16125-16215, 2020.

[59] J. Li, G. Yu, L. Pan et al., "Study of ciprofloxacin removal by biochar obtained from used tea leaves," Journal of Environmental Sciences, vol. 73, no. 1, pp. 20-30, 2018.

[60] T. H. Nguyen, T. H. Pham, H. T. Nguyen Thi et al., "Synthesis of iron-modified biochar derived from rice straw and its application to arsenic removal," Journal of Chemistry, vol. 2019, 2019.

[61] N. Acelas, S. M. Lopera, J. Porras, and R. A. Torres-Palma, "Evaluating the removal of the antibiotic cephalexin from aqueous solutions using an adsorbent obtained from palm oil fiber," Molecules, vol. 26, no. 11, Article ID 3340, 2021.

[62] H. Motojima, M. O’Villareal, J. Han, and H. Isoda, "Microarray analysis of immediate-type allergy in KU812 cells in response to fulvic acid," Cytotechnology, vol. 63, no. 2, pp. 181-190, 2011.

[63] M. K. Hossain, V. Strezov, K. Yin Chan, and P. F. Nelson, "Agronomic properties of wastewater sludge biochar and bioavailability of metals in production of cherry tomato (Lycopersicon esculentum)," Chemosphere, vol. 78, no. 9, pp. 1167-1171, 2010.

[64] W. Zhang, S. Mao, H. Chen, L. Huang, and R. Qiu, "Pb(II) and $\mathrm{Cr}(\mathrm{VI})$ sorption by biochars pyrolyzed from the municipal wastewater sludge under different heating conditions," Bioresource Technology, vol. 147, pp. 545-552, 2013.

[65] X. Han, M. Niu, X. Jiang, and J. Liu, "Combustion characteristics of sewage sludge in a fluidized bed," Industrial \& Engineering Chemistry Research, vol. 51, no. 32, pp. 1056510570, 2012.

[66] F. Zhu, L. Li, S. Ma, and Z. Shang, "Effect factors, kinetics and thermodynamics of remediation in the chromium contaminated soils by nanoscale zero valent $\mathrm{Fe} / \mathrm{Cu}$ bimetallic particles," Chemical Engineering Journal, vol. 302, pp. 663-669, 2016.

[67] H. M. Jang, S. Yoo, Y.-K. Choi, S. Park, and E. Kan, “Adsorption isotherm, kinetic modeling and mechanism of tetracycline on Pinus taeda-derived activated biochar," Bioresource Technology, vol. 259, pp. 24-31, 2018.

[68] E. Irving, A. D. Tagalakis, R. Maeshima et al., "The liposomal delivery of hydrophobic oxidovanadium complexes imparts highly effective cytotoxicity and differentiating capacity in neuroblastoma tumour cells," Scientific Reports, vol. 10, no. 1, pp. 16660-16716, 2020.

[69] N. Mo, Z. Zhu, Y. Zhu et al., "Purification behavior of Zn (II) in water by magnesium hydroxyapatite: surface complexation, and dissolution-precipitation," International Journal of Environmental Research and Public Health, vol. 17, no. 11, Article ID 3804, 2020.

[70] E. Čadková, M. Komárek, R. Kaliszová et al., “The influence of copper on tebuconazole sorption onto soils, humic substances, and ferrihydrite," Environmental Science and Pollution Research International, vol. 20, no. 6, pp. 4205-4215, 2013.

[71] D. Chaara, F. Bruna, K. Draoui, M. A. Ulibarri, C. Barriga, and I. Pavlovic, "Study of key parameters affecting adsorption of 
the herbicide Linuron on organohydrotalcites," Applied Clay Science, vol. 58, pp. 34-38, 2012.

[72] X. Song, D. Liu, G. Zhang, M. Frigon, X. Meng, and K. Li, "Adsorption mechanisms and the effect of oxytetracycline on activated sludge," Bioresource Technology, vol. 151, pp. 428431, 2014.

[73] F. Zhou, H. Wang, S. e. Fang, W. Zhang, and R. Qiu, "Pb(II), $\mathrm{Cr}(\mathrm{VI})$ and atrazine sorption behavior on sludge-derived biochar: role of humic acids," Environmental Science and Pollution Research, vol. 22, no. 20, pp. 16031-16039, 2015.

[74] X. Hu, J. Xie, W. Cai, R. Wang, and A. Davarpanah, "Thermodynamic effects of cycling carbon dioxide injectivity in shale reservoirs," Journal of Petroleum Science and Engineering, vol. 195, Article ID 107717, 2020.

[75] J. Zhao, G. Liang, X. Zhang et al., "Coating magnetic biochar with humic acid for high efficient removal of fluoroquinolone antibiotics in water," The Science of the Total Environment, vol. 688, pp. 1205-1215, 2019.

[76] G. Crini, A. Exposito Saintemarie, S. Rocchi et al., "Simultaneous removal of five triazole fungicides from synthetic solutions on activated carbons and cyclodextrin-based adsorbents," Heliyon, vol. 3, no. 8, Article ID e00380, 2017.

[77] C. W. Cheung, J. F. Porter, and G. McKay, "Sorption kinetic analysis for the removal of cadmium ions from effluents using bone char," Water Research, vol. 35, no. 3, pp. 605-612, 2001.

[78] J. Liang, Y. Fang, Y. Luo et al., "Magnetic nanoferromanganese oxides modified biochar derived from pine sawdust for adsorption of tetracycline hydrochloride," Environmental Science and Pollution Research, vol. 26, no. 6, pp. 5892-5903, 2019.

[79] X. Chen, G. Chen, L. Chen et al., "Adsorption of copper and zinc by biochars produced from pyrolysis of hardwood and corn straw in aqueous solution," Bioresource Technology, vol. 102, no. 19, pp. 8877-8884, 2011.

[80] Z. Wu, H. Zhong, X. Yuan et al., "Adsorptive removal of methylene blue by rhamnolipid-functionalized graphene oxide from wastewater," Water Research, vol. 67, pp. 330-344, 2014.

[81] S. Fan, Y. Wang, Z. Wang, J. Tang, J. Tang, and X. Li, "Removal of methylene blue from aqueous solution by sewage sludge-derived biochar: adsorption kinetics, equilibrium, thermodynamics and mechanism," Journal of Environmental Chemical Engineering, vol. 5, no. 1, pp. 601-611, 2017.

[82] M. J. K. Ahmed and M. Ahmaruzzaman, "A facile synthesis of $\mathrm{Fe} 3 \mathrm{O} 4$-charcoal composite for the sorption of a hazardous dye from aquatic environment," Journal of Environmental Management, vol. 163, pp. 163-173, 2015.

[83] Q. Zhou, B. Liao, L. Lin, W. Qiu, and Z. Song, "Adsorption of $\mathrm{Cu}$ (II) and $\mathrm{Cd}(\mathrm{II})$ from aqueous solutions by ferromanganese binary oxide-biochar composites," The Science of the Total Environment, vol. 615, pp. 115-122, 2018.

[84] M. J. Ahmed, P. U. Okoye, E. H. Hummadi, and B. H. Hameed, "High-performance porous biochar from the pyrolysis of natural and renewable seaweed (Gelidiella acerosa) and its application for the adsorption of methylene blue," Bioresource Technology, vol. 278, pp. 159-164, 2019.

[85] Y. Wang, Q. Yang, J. Chen et al., "Adsorption behavior of $\mathrm{Cr}(\mathrm{VI})$ by magnetically modified Enteromorpha prolifera based biochar and the toxicity analysis," Journal of Hazardous Materials, vol. 395, Article ID 122658, 2020.

[86] W. Gehling and B. Dellinger, "Environmentally persistent free radicals and their lifetimes in PM2.5," Environmental Science \& Technology, vol. 47, no. 15, pp. 8172-8178, 2013.
[87] H. Jia, G. Nulaji, H. Gao, F. Wang, Y. Zhu, and C. Wang, "formation and stabilization of environmentally persistent free radicals induced by the interaction of anthracene with Fe(III)-Modified clays," Environmental Science \& Technology, vol. 50, no. 12, pp. 6310-6319, 2016.

[88] L. W. Kiruri, L. Khachatryan, B. Dellinger, and S. Lomnicki, "Effect of copper oxide concentration on the formation and persistency of environmentally persistent free radicals (EPFRs) in particulates," Environmental Science \& Technology, vol. 48, no. 4, pp. 2212-2217, 2014.

[89] Z. Wang, J. Zhang, B. Hu, J. Yu, J. Wang, and X. Guo, "Graphene/Fe3O4 nanocomposite for effective removal of ten triazole fungicides from water solution: tebuconazole as an example for investigation of the adsorption mechanism by experimental and molecular docking study," Journal of the Taiwan Institute of Chemical Engineers, vol. 95, pp. 635-642, 2019.

[90] K. Valizadeh and A. Davarpanah, "Design and construction of a micro-photo bioreactor in order to dairy wastewater treatment by micro-algae: parametric study," Energy Sources, Part A: Recovery, Utilization, and Environmental Effects, vol. 42, no. 5, pp. 611-624, 2020.

[91] A. Davarpanah, "Parametric study of polymer-nanoparticlesassisted injectivity performance for axisymmetric two-phase flow in EOR processes," Nanomaterials, vol. 10, no. 9, Article ID $1818,2020$.

[92] A. Hgeig, M. Novaković, and I. Mihajlović, "Sorption of carbendazim and linuron from aqueous solutions with activated carbon produced from spent coffee grounds: equilibrium, kinetic and thermodynamic approach," Journal of Environmental Science and Health, Part B, vol. 54, no. 4, pp. 226-236, 2019.

[93] G. Fang, C. Zhu, D. D. Dionysiou, J. Gao, and D. Zhou, "Mechanism of hydroxyl radical generation from biochar suspensions: implications to diethyl phthalate degradation," Bioresource Technology, vol. 176, pp. 210-217, 2015.

[94] A. Davarpanah, "Feasible analysis of reusing flowback produced water in the operational performances of oil reservoirs," Environmental Science and Pollution Research, vol. 25, no. 35, pp. 35387-35395, 2018. 